\title{
Generalized coupled common fixed point results in partially ordered $A$-metric spaces
}

\author{
Mujahid Abbas ${ }^{1}$, Bashir Ali ${ }^{2}$ and Yusuf I Suleiman ${ }^{3 *}$
}

\section{"Correspondence:} yubram@yahoo.com

${ }^{3}$ Department of Mathematics, Kano

University of Science and

Technology, P.M.B. 3042, Wudil, Kano, Nigeria

Full list of author information is available at the end of the article

\begin{abstract}
Sedghi et al. (Mat. Vesn. 64(3):258-266, 2012) introduced the notion of a S-metric as a generalized metric in 3-tuples $S: X^{3} \rightarrow[0, \infty)$, where $X$ is a nonempty set. The aim of this paper is to introduce the concept of an $n$-tuple metric $A: X^{n} \rightarrow[0, \infty)$ and to study its basic topological properties. We also prove some generalized coupled common fixed point theorems for mixed weakly monotone maps in partially ordered A-metric spaces. Some examples are presented to support the results proved herein. Our results generalize and extend various results in the existing literature.
\end{abstract}

MSC: $47 \mathrm{H} 09 ; 47 \mathrm{H} 10 ; 54 \mathrm{H} 25$

Keywords: coupled common fixed point; 2-metric spaces; D-metric spaces; D*-metric spaces; G-metric spaces; S-metric spaces; A-metric spaces; mixed weakly monotone maps

\section{Introduction and preliminaries}

Many mathematical problems require one to find a distance between two or more objects which is not easy to measure precisely in general. There exist different approaches to obtaining the appropriate concept of a metric structure. Due to the need to construct a suitable framework to model several distinguished problems of practical nature, the study of generalized metric has attracted, and continues to attract the interest of many authors. Over the last few decades, a number of generalizations of metric space have thus appeared in many papers. These generalizations were then also used to extend the scope of the study of fixed point theory. For more discussions of such generalizations, we refer to [1-4], and [5].

In the sequel, the letters $\mathbb{R}, \mathbb{R}^{+}$, and $\mathbb{N}$ will denote the set of all real numbers, the set of all nonnegative real numbers, and the set of all positive integers, respectively.

In 1963, Gähler [2] introduced the notion of a 2-metric space as follows.

Definition 1.1 Let $X$ be a nonempty set. A function $d: X^{3} \rightarrow \mathbb{R}$ is said to be a 2-metric on $X$ if the following conditions hold:

(d1) For any distinct points $x, y \in X$ there is $z \in X$ such that $d(x, y, z) \neq 0$,

(d2) $d(x, y, z)=0$ if any two elements of the set $\{x, y, z\}$ in $X$ are equal,

(d3) $d(x, y, z)=d(x, z, y)=d(y, x, z)=d(z, x, y)=d(y, z, x)=d(z, y, x)$,

(d4) $d(x, y, z) \leq d(x, y, a)+d(x, a, z)+d(a, y, z)$ for all $x, y, z, a \in X$.

The pair $(X, d)$ is called a 2-metric space.

(c) 2015 Abbas et al.; licensee Springer. This article is distributed under the terms of the Creative Commons Attribution 4.0 International License (http://creativecommons.org/licenses/by/4.0/), which permits unrestricted use, distribution, and reproduction in any medium, provided you give appropriate credit to the original author(s) and the source, provide a link to the Creative Commons license, and indicate if changes were made. 
Gähler [2] claimed that 2-metric space is a generalization of an ordinary metric space. He mentioned in [6] that $d(x, y, z)$ geometrically represents the area of a triangle formed by the points $x, y, z \in X$ as its vertices.

On the other hand, Ha et al. [7] and Sharma [8] found some mathematical flaws in these claims. It was demonstrated in [8] that $d(x, y, z)$ does not always represent the area of a triangle formed by the points $x, y, z \in X$. Ha et al. [7] proved that the 2-metric is not sequentially continuous in each of its arguments whereas an ordinary metric satisfies this property.

In order to carry out meaningful studies of fixed point results, Dhage [1] suggested an improvement in the basic structure of 2-metric space.

In 1984, Dhage in his Ph.D. thesis [9] identified condition (d2) as a weakness in Gähler's theory of a 2-metric space. To overcome these problems, he then introduced the concept of a $D$-metric space.

Definition 1.2 Let $X$ be a nonempty set. A function $D: X^{3} \rightarrow \mathbb{R}$ is called a $D$-metric on $X$ if it satisfies the following conditions:

(D1) $D(x, y, z) \geq 0$ for all $x, y, z \in X$ and equality holds if and only if $x=y=z$,

(D2) $D(x, y, z)=D(x, z, y)=D(y, x, z)=D(z, x, y)=D(y, z, x)=D(z, y, x)$,

(D3) $D(x, y, z) \leq D(x, y, a)+D(x, a, z)+D(a, y, z)$ for all $x, y, z, a \in X$.

The pair $(X, D)$ is called a $D$-metric space.

It is important to note that condition (d3) and (D2) are equivalent. Condition (d4) and (D3) are also equivalent, whereas (d1) and (d2) have been replaced by (D1). Dhage [1] modified condition (d2) to obtain the natural nonnegativity condition of ordinary metric.

Dhage [10] then studied topological properties of $D$-metric space in a series of papers. The notions of open balls and sequential continuity in $D$-metric space were introduced in [11]. It was claimed that the $D$-metric induces a Hausdorff topology, and that the family of all open balls in a $D$-metric space forms a base for such a topology. Naidu et al. [12] proved that the concepts of convergent sequences and sequential continuity are not well defined in $D$-metric spaces. Naidu et al. [13] pointed out some drawbacks in the idea of open balls in D-metric space. In 2003, Mustafa and Sims [14] identified condition (D3) as a weakness in Dhage's theory of $D$-metric space.

In 2006, Mustafa and Sims [5] introduced the notion of G-metric space and suggested an important generalization of metric space as follows.

Definition 1.3 Let $X$ be a nonempty set. A function $G: X^{3} \rightarrow \mathbb{R}^{+}$is called a $G$-metric on $X$ if it satisfies the following conditions: For all $x, y, z, a \in X$,

(G1) $G(x, y, z)=0$ if $x=y=z$,

(G2) $0 \leq G(x, y, y)$ for all $x, y \in X$ with $x \neq y$,

(G3) $G(x, x, y) \leq G(x, y, z)$ for all $x, y, z \in X$ with $z \neq y$,

(G4) $G(x, y, z)=G(x, z, y)=G(y, x, z)=G(z, x, y)=G(y, z, x)=G(z, y, x)$,

(G5) $G(x, y, z) \leq G(x, a, a)+G(a, y, z)$.

The pair $(X, G)$ is called a $G$-metric space.

Note that condition (D1) has been replaced with (G1), (G2), and (G3). Condition (D2) is equivalent to (G4) and condition (D3) has been replaced by (G5). The deficiency of Dhage's theory of $D$-metric is thus corrected. Subsequently, Mustafa and Sims [5] studied 
some topological properties of $G$-metric space and afterwards some authors have obtained generalized fixed point theorems in the setup of $G$-metric space; see for example [15].

Unlike in the theory of $G$-metric space, where condition (D1) was replaced with the three separate axioms (G1), (G2), and (G3), Sedghi et al. [3] observed that condition (D1) can be replaced with two axioms and thus introduced the notion of a $D^{*}$-metric space as follows.

Definition 1.4 Let $X$ be a nonempty set. A function $D^{*}: X^{3} \rightarrow \mathbb{R}^{+}$is called a $D^{*}$-metric on $\mathrm{X}$ if it satisfies the following conditions: For all $x, y, z, a \in X$,

(D*1) $D^{*}(x, y, z) \geq 0$,

(D*2) $D^{*}(x, y, z)=0$ if and only if $x=y=z$,

(D*3) $D^{*}(x, y, z)=D^{*}(x, z, y)=D^{*}(y, x, z)=D^{*}(z, x, y)=D^{*}(y, z, x)=D^{*}(z, y, x)$,

(D*4) $D^{*}(x, y, z) \leq D^{*}(x, y, a)+D^{*}(a, z, z)$.

The pair $\left(X, D^{*}\right)$ is called a $D^{*}$-metric space.

Note that condition (D1) has been replaced with (D*1) and (D*2). Condition (D2) and (D*3) are equivalent. Condition (D3) has been replaced with (D*4). The tetrahedral inequality in $D$-metric has been replaced with the prototypical rectangular inequality adopted by Mustafa and Sims [5]. Therefore $D^{*}$-metric space theory can be viewed as an improved version of Dhage's theory of $D$-metric space. To the best of our knowledge, little or no work has appeared on the topological properties of $D^{*}$-metric space. Some interesting fixed point results in $D^{*}$-metric space have been obtained in [16].

Every G-metric space is a $D^{*}$-metric space. Indeed conditions (G1), (G2), and (G3) imply $\left(D^{*} 1\right)$. Axioms (G1) and (D*2) are equivalent. (G4) and (D*3) are also equivalent, whereas (G4) and (G5) imply ( $\left.D^{*} 4\right)$. The converse, however, is false in general; a $D^{*}$-metric space is not necessarily a $G$-metric space. To see this let $X=\mathbb{R}$ and $D^{*}: X^{3} \rightarrow \mathbb{R}^{+}$be a function defined by

$$
D^{*}(x, y, z)=|2 z-x-y|+|2 x-y-z|+|2 y-x-z| .
$$

Clearly ( $\left.\mathrm{D}^{*} 1\right)$ holds, that is, $D^{*}(x, y, z) \geq 0$ for all $x, y, z \in X$.

Note that $D^{*}(x, y, z)=0 \Leftrightarrow|2 z-x-y|=0,|2 x-y-z|=0$, and $|2 y-x-z|=0 \Leftrightarrow 2 z-$ $x=y, 2 x-y=z$, and $2 y-x=z \Leftrightarrow x=y=z$. Thus condition (D*2) holds. As $D^{*}(x, y, z)=$ $D^{*}(x, z, y)=D^{*}(y, x, z)=D^{*}(z, x, y)=D^{*}(y, z, x)=D^{*}(z, y, x),\left(D^{*} 3\right)$ is valid for all $x, y, z \in X$. If $x, y, z, a \in X$, then we have

$$
\begin{aligned}
D^{*}(x, y, z) & =|2 z-x-y|+|2 x-y-z|+|2 y-x-z| \\
& \leq|2 a-x-y|+2|z-a|+|2 x-y-a|+|z-a|+|2 y-x-a|+|z-a| \\
& =|2 a-x-y|+|2 x-y-a|+|2 y-x-a|+4|z-a| .
\end{aligned}
$$

This implies $D^{*}(x, y, z) \leq D^{*}(x, y, a)+D^{*}(a, z, z)$. Hence $\left(X, D^{*}\right)$ is a $D^{*}$-metric space. Now, if $x=4, y=-6$, and $z=2$, then $G(4,4,-6)=40$ and $G(4,-6,2)=36$. Thus condition (G3) fails. So not every $D^{*}$-metric space needs to be a $G$-metric space. 
Sedghi et al. [4] identified condition (G3) as a peculiar limitation of the G-metric space but classified the symmetry condition as a common weakness of both $G$ - and $D^{*}$-metric spaces.

To overcome these difficulties, Sedghi et al. [4] introduced a new generalized metric space called an $S$-metric space.

Definition 1.5 Let $X$ be a nonempty set. Suppose a function $S: X^{3} \rightarrow[0, \infty)$ satisfies the following conditions:

(S1) $S(x, y, z) \geq 0$,

(S2) $S(x, y, z)=0$ if and only if $x=y=z$,

(S3) $S(x, y, z) \leq S(x, x, a)+S(y, y, a)+S(z, z, a)$ for any $x, y, z, a \in X$.

Then the ordered pair $(X, S)$ is called an $S$-metric space.

It is observed that the shortfalls of the G-metric are corrected and conditions $\left(D^{*} 3\right)$ and $\left(D^{*} 4\right)$ are replaced with (S3).

Proposition 1.6 Every $D^{*}$-metric space is an S-metric space.

Proof Let $\left(X, D^{*}\right)$ be a $D^{*}$-metric space. From Definitions 1.4 and 1.5 , we see that:

(1) (D*1) and (S1) are equivalent,

(2) (D*2) is equivalent to (S2), and

(3) (D*3) and ( $\left.D^{*} 4\right)$ imply (S3). Indeed, for all $x, y, z, a \in X$, we have

$$
\begin{aligned}
D^{*}(x, y, z) & \leq D^{*}(x, y, a)+D^{*}(a, z, z) \\
& =D^{*}(a, x, y)+D^{*}(a, z, z) \\
& \leq D^{*}(a, x, a)+D^{*}(a, a, y)+D^{*}(a, z, z) \\
& =D^{*}(x, x, a)+D^{*}(y, y, a)+D^{*}(z, z, a) .
\end{aligned}
$$

Thus, every $D^{*}$-metric space is an $S$-metric space.

But the converse of Proposition 1.6 does not hold in general. To prove this, let $X=\mathbb{R}$. Define the mapping $S: X \times X \times X \rightarrow[0, \infty)$ by

$$
S(x, y, z)=|2 x-y-z|+|z-y|
$$

for all $x, y, z \in X$. Obviously, conditions (S1) and (S2) are satisfied. We shall show that, for all $x, y, z \in X,(\mathrm{~S} 3)$ is valid.

$$
\begin{aligned}
S(x, y, z) & =|2 x-y-z|+|z-y| \\
& \leq 2|x-a|+2|y-a|+2|z-a| \\
& =S(x, x, a)+S(y, y, a)+S(z, z, a) .
\end{aligned}
$$

Therefore $(X, S)$ is an $S$-metric space. Note that $D^{*}(4,7,3)=6 \neq 8=D^{*}(3,4,7)$. Hence $(X, S)$ is not a $D^{*}$-metric space. 
Proposition 1.7 The S-metric space is a generalization of the G-metric space and the D*metric space.

Proof The proof is straightforward.

Modification, enrichment, and extension of the structure of domains of the definition to obtain more general spaces is one of the active research areas in fixed point theory. One of the basic and the most widely applied fixed point theorems in mathematical analysis is the 'Banach (or Banach-Caccioppoli) contraction principle'. It states that if $(X, d)$ is a complete metric space and $f: X \rightarrow X$ satisfies

$$
d(f x, f y) \leq k d(x, y)
$$

for all $x, y \in X$, with $k \in(0,1)$, then $f$ has a unique fixed point. This result is simple and powerful with a wide range of applications in science and engineering. It can be employed to prove the existence of solution of differential or integral equations including iterative methods for solving linear, nonlinear, differential, integral, and difference equations (see for example Samet [17], Sedghi and Dung [18], Lakshmikantham and Ćirić [19], and Berinde and Vetro [20]) to mention just a few.

Definition 1.8 (see [21]) Let $(X, \leq)$ be a partially ordered set. A mapping $f: X^{2} \rightarrow X$ is said to have mixed monotone property on $X$, if for any $x, y \in X, x_{1}, x_{2} \in X, x_{1} \leq x_{2} \Rightarrow f\left(x_{1}, y\right) \leq$ $f\left(x_{2}, y\right)$ and $y_{1}, y_{2} \in X, y_{1} \leq y_{2} \Rightarrow f\left(x, y_{1}\right) \geq f\left(x, y_{2}\right)$.

An element $(x, y) \in X \times X$ is called a coupled fixed point of $f$ if $x=f(x, y)$ and $y=f(y, x)$. In 2006, Bhaskar and Lakshmikantham [21] initiated the study of coupled fixed points and mixed monotone mapping in the setup of metric spaces, which provided powerful tools for solving complex problems; and therefore numerous interesting results on coupled fixed point theorems for various classes of contractive-type mappings in partially ordered metric spaces have been proved; see for example [7, 22-25], and the references therein. Gordji et al. [26] introduced the concepts of coupled common fixed points and mixed weakly monotone pair of mappings as follows.

Definition 1.9 (see [26]) Let $(X, \leq)$ be a partially ordered set and $f, g: X^{2} \rightarrow X$ be two maps. The pair $(f, g)$ is said to have the mixed weakly monotone property on $X$ if, for all $x, y \in X, x \leq f(x, y), y \geq f(y, x)$ imply $f(x, y) \leq g(f(x, y), f(y, x)), f(y, x) \geq g(f(y, x), f(x, y))$ and $x \leq g(x, y), y \geq g(y, x)$ imply $g(x, y) \leq f(g(x, y), g(y, x)), g(y, x) \geq f(g(y, x), g(x, y))$.

An element $(x, y) \in X \times X$ is called a coupled common fixed point of $f$ and $g$ if $x=f(x, y)$, $y=f(y, x), x=g(x, y)$ and $y=g(y, x)$. They proved the following result.

Theorem 1.10 (see [26]) Let $(X, \leq, d)$ be a partially ordered complete metric space, $f, g$ : $X^{2} \rightarrow X$ be the mappings such that the pair $(f, g)$ has mixed weakly monotone property on $X$. Suppose that there exist $p, q, r, s \geq 0$, with $p+q+r+2 s<1$ such that

$$
\begin{aligned}
d(f(x, y), g(u, v)) \leq & \left.\frac{p}{2} D((x, y),(u, v))+\frac{q}{2} D((x, y), f(y, x))\right) \\
& +\frac{r}{2} D((u, v),(g(u, v), g(v, u)))
\end{aligned}
$$




$$
\begin{aligned}
& +\frac{s}{2} D((x, y),(g(u, v), g(v, u))) \\
& +\frac{s}{2} D((u, v),(f(x, y), f(y, x)))
\end{aligned}
$$

holds for all $x, y, u, v \in X$ with $x \leq u$ and $y \geq v$. Let $x_{0}, y_{0} \in X$ be such that $x_{0} \leq$ $f\left(x_{0}, y_{0}\right), f\left(y_{0}, x_{0}\right) \leq y_{0}$ or $x_{0} \leq g\left(x_{0}, y_{0}\right), g\left(y_{0}, x_{0}\right) \leq y_{0}$. If $f$ or $g$ is continuous, then $f$ and $g$ have a coupled common fixed point in $X$.

Furthermore, assume that $X$ has the following properties:

(a) if $\left\{x_{n}\right\}$ is an increasing sequence with $x_{n} \rightarrow x$, then $x_{n} \leq x$ for all $n \geq 1$;

(b) if $\left\{y_{n}\right\}$ is a decreasing sequence with $y_{n} \rightarrow y$, then $y \leq y_{n}$ for all $n \geq 1$.

Then $f$ and $g$ have a coupled common fixed point in $X$.

Recently, Dung [27] generalized the results of Gordji et al. [26] in the framework of an $S$-metric space. He proved the following theorem.

Theorem 1.11 Let $(X, \leq, S)$ be a complete partially ordered $S$-metric space, $f, g: X^{2} \rightarrow X$ be two maps such that the pair $(f, g)$ has mixed weakly monotone property on $X$. Suppose that $x_{0}, y_{0} \in X$ are such that $x_{0} \leq f\left(x_{0}, y_{0}\right), f\left(y_{0}, x_{0}\right) \leq y_{0}$ or $x_{0} \leq g\left(x_{0}, y_{0}\right), g\left(y_{0}, x_{0}\right) \leq y_{0}$, and there exist $p, q, r, s \geq 0$, satisfying $p+q+r+2 s<1$ and

$$
\begin{aligned}
S(f(x, y), f(x, y), g(u, v)) \leq & \frac{p}{2} D((x, y),(x, y),(u, v))+\frac{q}{2} D((x, y),(x, y), f(y, x)) \\
& +\frac{r}{2} D((u, v),(u, v),(g(u, v), g(v, u))) \\
& +\frac{s}{2} D((x, y),(x, y),(g(u, v), g(v, u))) \\
& +\frac{s}{2} D((u, v),(u, v),(f(x, y), f(y, x)))
\end{aligned}
$$

for any $x, y, u, v \in X$ with $x \leq u$ and $y \geq v$. Assume $f$ or $g$ is continuous or $X$ has the following properties:

(a) if $\left\{x_{k}\right\}$ is an increasing sequence with $x_{k} \rightarrow x$, then $x_{k} \leq x$ for all $k \in \mathbb{N}$;

(b) if $\left\{x_{k}\right\}$ is a decreasing sequence with $x_{k} \rightarrow x$, then $x \leq x_{k}$ for all $k \in \mathbb{N}$.

Then $f$ and $g$ have a coupled common fixed point in $X$.

It is our purpose in this paper to first propose a generalization of the $S$-metric space, called an $A$-metric space, and then prove some coupled common fixed point theorems for mixed weakly monotone maps in partially ordered $A$-metric spaces. Our results extend, unify, and generalize comparable results in [4, 26, 27], and [21].

\section{A-metric space}

We now present the concept of an $A$-metric space and study some of its properties needed in the sequel.

Definition 2.1 Let $X$ be a nonempty set. A function $A: X^{n} \rightarrow[0, \infty)$ is called an $A$-metric on $X$ if for any $x_{i}, a \in X, i=1,2, \ldots, n$, the following conditions hold:

(A1) $A\left(x_{1}, x_{2}, x_{3}, \ldots, x_{n-1}, x_{n}\right) \geq 0$,

(A2) $A\left(x_{1}, x_{2}, x_{3}, \ldots, x_{n-1}, x_{n}\right)=0$ if and only if $x_{1}=x_{2}=x_{3}=\cdots=x_{n-1}=x_{n}$, 
(A3)

$$
\begin{aligned}
A\left(x_{1}, x_{2}, x_{3}, \ldots, x_{n-1}, x_{n}\right) \leq & A\left(x_{1}, x_{1}, x_{1}, \ldots,\left(x_{1}\right)_{(n-1)}, a\right) \\
& +A\left(x_{2}, x_{2}, x_{2}, \ldots,\left(x_{2}\right)_{(n-1)}, a\right) \\
& +A\left(x_{3}, x_{3}, x_{3}, \ldots,\left(x_{3}\right)_{(n-1)}, a\right) \\
& \vdots \\
& +A\left(x_{(n-1)}, x_{(n-1)}, x_{(n-1)}, \ldots,\left(x_{(n-1)}\right)_{(n-1)}, a\right) \\
& +A\left(x_{n}, x_{n}, x_{n}, \ldots,\left(x_{n}\right)_{(n-1)}, a\right) .
\end{aligned}
$$

The pair $(X, A)$ is called an $A$-metric space.

Note that $A$-metric space is an $n$-dimensional $S$-metric space. Therefore the ordinary metric $d$ and $S$-metric are special cases of an $A$-metric with $n=2$ and $n=3$, respectively.

Lemma 2.2 Let $(X, A)$ be A-metric space. Then $A(x, x, x, \ldots, x, y)=A(y, y, y, \ldots, y, x)$ for all $x, y \in X$.

Proof Applying condition (A3) of an A-metric, we obtain

$$
\begin{aligned}
A(x, x, x, \ldots, x, y) \leq & A(x, x, x, \ldots, x, x) \\
& +A(x, x, x, \ldots, x, x) \\
& \vdots \\
& +A(x, x, x, \ldots, x, x) \\
& +A(y, y, y, \ldots, y, x) \\
= & A(y, y, y, \ldots, y, x) .
\end{aligned}
$$

In a similar fashion

$$
\begin{aligned}
A(y, y, y, \ldots, y, x) \leq & A(y, y, y, \ldots, y, y) \\
& +A(y, y, y, \ldots, y, y) \\
& \vdots \\
& +A(y, y, y, \ldots, y, y) \\
& +A(x, x, x, \ldots, x, y) \\
= & A(x, x, x, \ldots, x, y) .
\end{aligned}
$$

The result follows from (2.1) and (2.2).

Example 2.3 Let $X=\mathbb{R}$. Define a function $A: X^{n} \rightarrow[0, \infty)$ by

$$
\begin{aligned}
A\left(x_{1}, x_{2}, x_{3}, \ldots, x_{n-1}, x_{n}\right)= & \left|x_{1}-x_{2}\right|+\left|x_{1}-x_{3}\right|+\cdots+\left|x_{1}-x_{n}\right| \\
& +\left|x_{2}-x_{3}\right|+\left|x_{2}-x_{4}\right|+\cdots+\left|x_{2}-x_{n}\right|
\end{aligned}
$$




$$
\begin{aligned}
& \vdots \\
& +\left|x_{n-2}-x_{n-1}\right|+\left|x_{n-2}-x_{n}\right|+\left|x_{n-1}-x_{n}\right| \\
= & \sum_{i=1}^{n} \sum_{i<j}\left|x_{i}-x_{j}\right| .
\end{aligned}
$$

Then $(X, A)$ is a usual $A$-metric space.

Example 2.4 Let $X=\mathbb{R}$. Define a function $A: X^{n} \rightarrow[0, \infty)$ by

$$
\begin{aligned}
A\left(x_{1}, x_{2}, x_{3}, \ldots, x_{n-1}, x_{n}\right)= & \left|x_{n}+x_{n-1}+\cdots+x_{2}-(n-1) x_{1}\right| \\
& +\left|x_{n}+x_{n-1}+\cdots+x_{3}-(n-2) x_{2}\right| \\
& \vdots \\
& +\left|x_{n}+x_{n-1}+x_{n-2}-3 x_{n-3}\right| \\
& +\left|x_{n}+x_{n-1}-2 x_{n-2}\right| \\
& +\left|x_{n}-x_{n-1}\right| .
\end{aligned}
$$

Then $(X, A)$ is an $A$-metric space.

Lemma 2.5 Let $(X, A)$ be A-metric space. Then for all $x, y \in X$ we have $A(x, x, x, \ldots, x, z) \leq$ $(n-1) A(x, x, x, \ldots, x, y)+A(z, z, z, \ldots, z, y)$ and $A(x, x, x, \ldots, x, z) \leq(n-1) A(x, x, x, \ldots, x, y)+$ $A(y, y, y, \ldots, y, z)$.

Proof Applying Lemma 2.2 and condition (A3) of the $A$-metric, we obtain

$$
\begin{aligned}
A(x, x, x, \ldots, x, z) \leq & A(x, x, x, \ldots, x, y) \\
& +A(x, x, x, \ldots, x, y) \\
& \vdots \\
& +A(x, x, x, \ldots, x, y) \\
& +A(z, z, z, \ldots, z, y) \\
= & (n-1) A(x, x, x, \ldots, x, y)+A(z, z, z, \ldots, z, y) \\
= & (n-1) A(x, x, x, \ldots, x, y)+A(y, y, y, \ldots, y, z),
\end{aligned}
$$

which implies

$$
\begin{aligned}
A(x, x, x, \ldots, x, z) & \leq(n-1) A(x, x, x, \ldots, x, y)+A(z, z, z, \ldots, z, y) \\
& =(n-1) A(x, x, x, \ldots, x, y)+A(y, y, y, \ldots, y, z) .
\end{aligned}
$$

Hence the result. 
Lemma 2.6 Let $(X, A)$ be A-metric space. Then $\left(X^{2}, D_{A}\right)$ is A-metric space on $X \times X$ with the metric $D_{A}$ given by $D\left(\left(x_{1}, y_{1}\right),\left(x_{2}, y_{2}\right), \ldots,\left(x_{n}, y_{n}\right)\right)=A\left(x_{1}, x_{2}, x_{3}, \ldots, x_{n},\right)+A\left(y_{1}, y_{2}, y_{3}\right.$, $\left.\ldots, y_{n}\right)$ for all $x_{i}, y_{j} \in X, i, j=1,2, \ldots, n$.

Proof For all $x_{i}, y_{j} \in X, i, j=1,2, \ldots, n$, we have $D\left(\left(x_{1}, y_{1}\right),\left(x_{2}, y_{2}\right),\left(x_{3}, y_{3}\right), \ldots,\left(x_{n}, y_{n}\right)\right) \geq$ 0 . Note that $D\left(\left(x_{1}, y_{1}\right),\left(x_{2}, y_{2}\right),\left(x_{3}, y_{3}\right), \ldots,\left(x_{n}, y_{n}\right)\right)=0 \Leftrightarrow A\left(x_{1}, x_{2}, x_{3}, \ldots, x_{n}\right)+A\left(y_{1}, y_{2}, y_{3}\right.$, $\left.\ldots, y_{n}\right)=0 \Leftrightarrow A\left(x_{1}, x_{2}, x_{3}, \ldots, x_{n},\right)=0$ and $A\left(y_{1}, y_{2}, y_{3}, \ldots, y_{n}\right)=0 \Leftrightarrow x_{1}=x_{2}=x_{3}=\cdots=x_{n}$ and $y_{1}=y_{2}=y_{3}=\cdots=y_{n} \Leftrightarrow\left(x_{1}, y_{1}\right)=\left(x_{2}, y_{2}\right)=\left(x_{3}, y_{3}\right)=\cdots=\left(x_{n}, y_{n}\right)$. Consider

$$
\begin{aligned}
D( & \left.\left(x_{1}, y_{1}\right),\left(x_{2}, y_{2}\right), \ldots,\left(x_{n}, y_{n}\right)\right) \\
= & A\left(x_{1}, x_{2}, \ldots, x_{n},\right)+A\left(y_{1}, y_{2}, \ldots, y_{n}\right) \\
\leq & A\left(x_{1}, x_{1}, x_{1}, \ldots, x_{1}, a\right)+A\left(x_{2}, x_{2}, x_{2}, \ldots, x_{2}, a\right) \\
& \vdots \\
& +A\left(x_{n}, x_{n}, x_{n}, \ldots, x_{n}, a\right) \\
& +A\left(y_{1}, y_{1}, y_{1}, \ldots, y_{1}, b\right)+A\left(y_{2}, y_{2}, y_{2}, \ldots, y_{2}, b\right) \\
& \vdots \\
& +A\left(y_{n}, y_{n}, y_{n}, \ldots, y_{n}, b\right) \\
= & A\left(x_{1}, x_{1}, x_{1}, \ldots, x_{1}, a\right)+A\left(y_{1}, y_{1}, y_{1}, \ldots, y_{1}, b\right) \\
& +A\left(x_{2}, x_{2}, x_{2}, \ldots, x_{2}, a\right)+A\left(y_{2}, y_{2}, y_{2}, \ldots, y_{2}, b\right) \\
& \vdots \\
& + \\
& +A\left(x_{n}, x_{n}, x_{n}, \ldots, x_{n}, a\right)+A\left(y_{n}, y_{n}, y_{n}, \ldots, y_{n}, b\right) \\
= & D\left(\left(x_{1}, y_{1}\right),\left(x_{1}, y_{1}\right), \ldots,\left(x_{1}, y_{1}\right),(a, b)\right) \\
& +D\left(\left(x_{2}, y_{2}\right),\left(x_{2}, y_{2}\right), \ldots,\left(x_{2}, y_{2}\right),(a, b)\right) \\
& + \\
& + \\
& + \\
& +D\left(\left(x_{1}, y_{1}\right),\left(x_{2}, y_{2}\right), \ldots,\left(x_{n}, y_{n}\right)\right) \\
\leq & \left.D\left(\left(x_{1}, y_{1}\right),\left(x_{1}, y_{1}\right), \ldots, y_{n}\right),\left(x_{1}, y_{1}\right),(a, b)\right) \\
& +
\end{aligned}
$$

Hence $\left(X^{2}, D_{A}\right)$ is an $A$-metric space on $X \times X$. 
Remark 2.7 It is easy to see that whenever $n=2$, we would get $D\left(\left(x_{1}, y_{1}\right),\left(x_{2}, y_{2}\right)\right)=$ $d\left(x_{1}, x_{2}\right)+d\left(y_{1}, y_{2}\right)$ where $D_{A}=D_{d}$ and if we put $n=3$, then we have $D\left(\left(x_{1}, y_{1}\right),\left(x_{2}, y_{2}\right)\right.$, $\left.\left(x_{3}, y_{3}\right)\right)=S\left(x_{1}, x_{2}, x_{3}\right)+S\left(y_{1}, y_{2}, y_{3}\right)$.

Note also that the following implications hold.

$G$-metric space $\Rightarrow D^{*}$-metric space $\Rightarrow S$-metric space $\Rightarrow A$-metric space.

Definition 2.8 The $A$-metric space $(X, A)$ is said to be bounded if there exists a constant $r>0$ such that $A(x, x, x, \ldots, x, y) \leq r$ for all $x, y \in X$. Otherwise, $X$ is unbounded.

Definition 2.9 Given a point $x_{0}$ in $A$-metric space $(X, A)$ and a positive real number $r$, the set $B\left(x_{0}, r\right)=\left\{y \in X: A\left(y, y, y, \ldots, y, x_{0}\right)<r\right\}$ is called an open ball centered at $x_{0}$ with radius $r$.

The set $\overline{B\left(x_{0}, r\right)}=\left\{y \in X: A\left(y, y, y, \ldots, y, x_{0}\right) \leq r\right\}$ is called a closed ball centered at $x_{0}$ with radius $r$.

Definition 2.10 A subset $G$ in $A$-metric space $(X, A)$ is said to be an open set if for each $x \in G$ there exists an $r>0$ such that $B(x, r) \subset G$. A subset $F \subset X$ is called closed if $X \backslash F$ is open.

Lemma 2.11 In any A-metric space $(X, A)$, each open ball is an open set in $X$ and each closed ball is also a closed set in $X$.

Proof Let $y \in B(x, r)$ be arbitrary. Thus $A(y, y, y, \ldots, y, x)<r$. Set $s=r-A(y, y, y, \ldots, y, x)>0$. We show that $B(y, s) \subset B(x, r)$. For this, let $z \in B(y, s)$. Then by the condition (A3), we have

$$
A(z, z, z, \ldots, z, x) \leq A(y, y, y, \ldots, y, x)+A(z, z, z, \ldots, z, y) .
$$

This implies $A(z, z, z, \ldots, z, x)<A(y, y, y, \ldots, y, x)+s=r$. Hence $z \in B(x, r)$. Thus $B(x, r)$ is open. It is easy to show that $X \backslash \overline{B(x, r)}$ is open and hence $\overline{B(x, r)}$ is closed.

Theorem 2.12 Let $(X, A)$ be A-metric space, then:

(i) An arbitrary union and finite intersection of open balls $B(x, r) \in X$ is open.

(ii) An arbitrary intersection and finite union of closed balls $B(x, r) \in X$ is closed.

Proof The proof is direct and similar to the case of an ordinary metric space.

Theorem 2.13 The collection $\Im=\{B(x, r): x \in X, r>0\}$ of all balls in $A$-metric space $(X, A)$ is a basis for a topology $\tau$ on $X$.

Definition 2.14 Let $(X, A)$ be $A$-metric space. A sequence $\left\{x_{k}\right\}$ in $X$ is said to converge to a point $x \in X$. If $A\left(x_{k}, x_{k}, x_{k}, \ldots, x_{k}, x\right) \rightarrow 0$ as $k \rightarrow \infty$.

That is, for each $\epsilon \geq 0$, there exists $N \in \mathbb{N}$ such that for all $k \geq N$ we have $A\left(x_{k}, x_{k}, x_{k}\right.$, $\left.\ldots, x_{k}, x\right) \leq \epsilon$ and we write $\lim _{k \rightarrow \infty} x_{k}=x$.

Lemma 2.15 Let $(X, A)$ be A-metric space. If the sequence $\left\{x_{k}\right\}$ in $X$ converges to a point $x$, then $x$ is unique. 
Proof Suppose $\left\{x_{k}\right\}$ converges to $x$ and $y$. Then given $\epsilon>0$, there exist $N_{1}, N_{2} \in \mathbb{N}$ such that for all $k \geq N_{1}$ we have $A\left(x_{k}, x_{k}, x_{k}, \ldots, x_{k}, x\right)<\frac{\epsilon}{2(n-1)}$ and for every $k \geq N_{2}$ we get $A\left(x_{k}, x_{k}, x_{k}, \ldots, x_{k}, y\right)<\frac{\epsilon}{2}$. Choose $N=\max \left\{N_{1}, N_{2}\right\}$, therefore, for all $k \geq N$, we have

$$
\begin{aligned}
A(x, x, x, \ldots, x, y) & \leq(n-1) A\left(x, x, x, \ldots, x, x_{k}\right)+A\left(x_{k}, x_{k}, x_{k}, \ldots, x_{k}, y\right) \\
& =(n-1) A\left(x_{k}, x_{k}, x_{k}, \ldots, x_{k}, x\right)+A\left(x_{k}, x_{k}, x_{k}, \ldots, x_{k}, y\right) \\
& <(n-1) \times \frac{\epsilon}{2(n-1)}+\frac{\epsilon}{2} \\
& =\epsilon .
\end{aligned}
$$

Since $\epsilon$ is arbitrary, we have $A(x, x, x, \ldots, x, y)=0$ and so $x=y$. Establishing the uniqueness of $\left\{x_{k}\right\}$.

Definition 2.16 Let $(X, A)$ be $A$-metric space. A sequence $\left\{x_{k}\right\}$ in $X$ is called a Cauchy sequence if $A\left(x_{k}, x_{k}, x_{k}, \ldots, x_{k}, x_{m}\right) \rightarrow 0$ as $k, m \rightarrow \infty$.

That is, for each $\epsilon \geq 0$, there exists $N \in \mathbb{N}$ such that for all $k, m \geq N$ we have $A\left(x_{k}, x_{k}, x_{k}, \ldots, x_{k}, x_{m}\right) \leq \epsilon$.

Lemma 2.17 Every convergent sequence in A-metric space is a Cauchy sequence.

Proof Let $\left\{x_{k}\right\}$ be a convergent sequence in $(X, A)$. Let $\lim _{k \rightarrow \infty} x_{k}=x$. Then given $\epsilon>0$, there exist $N_{1}, N_{2} \in \mathbb{N}$ such that for all $k \geq N_{1}$ we have $A\left(x_{k}, x_{k}, x_{k}, \ldots, x_{k}, x\right)<\frac{\epsilon}{2(n-1)}$ and for all $m \geq N_{2}$ we get $A\left(x_{m}, x_{m}, x_{m}, \ldots, x_{m}, x\right)<\frac{\epsilon}{2}$. Put $N=\max \left\{N_{1}, N_{2}\right\}$. Therefore, for all $k, m \geq N$, we obtain

$$
\begin{aligned}
A\left(x_{k}, x_{k}, x_{k}, \ldots, x_{k}, x_{m}\right) \leq & (n-1) A\left(x_{k}, x_{k}, x_{k}, \ldots, x_{k}, x\right) \\
& +A\left(x_{m}, x_{m}, x_{m}, \ldots, x_{m}, x\right) \\
< & (n-1) \times \frac{\epsilon}{2(n-1)}+\frac{\epsilon}{2} \\
= & \epsilon .
\end{aligned}
$$

This implies that $\left\{x_{k}\right\}$ is a Cauchy sequence.

Remark 2.18 The converse of Lemma 2.17 does not hold in general. A Cauchy sequence in an $A$-metric space does not need to be convergent. To see this we consider the space $(X=\mathbb{Q}, A)$ with the $A$-metric defined as in Example 2.3. Let $\left\{x_{k}\right\}$ be a sequence defined by $x_{k}=\left(1+\frac{1}{k}\right)^{k}$. Observe that $x_{k} \in \mathbb{Q} \forall k \in \mathbb{N}$. Furthermore,

$$
\begin{aligned}
A\left(x_{k}, x_{k}, x_{k}, \ldots, x_{k}, x_{m}\right) & =(n-1)\left|x_{k}-x_{m}\right| \\
& =(n-1)\left|\left(1+\frac{1}{k}\right)^{k}-\left(1+\frac{1}{m}\right)^{m}\right| \rightarrow 0
\end{aligned}
$$

as $k, m \rightarrow \infty$. Thus, $\left\{x_{k}\right\}$ is Cauchy. But $x_{k} \rightarrow e$ as $k \rightarrow \infty$ and $e$ is not in $\mathbb{Q}$. Hence $\left\{x_{k}\right\}$ does not converge.

Definition 2.19 The $A$-metric space $(X, A)$ is said to be complete if every Cauchy sequence in $X$ is convergent. 
Definition 2.20 Let $\left(X, A_{X}\right)$ and $\left(Z, A_{Z}\right)$ be $A$-metric spaces.

A function $f: X \rightarrow Z$ is said to be continuous at a point $x_{0} \in X$. If $f^{-I}(G)$ is open in $X$, for each open set $G$ in $Z$. The function $f$ is continuous on $X$ if it is continuous at each points of $X$.

Theorem 2.21 Let $\left(X, A_{X}\right)$ and $\left(Z, A_{Z}\right)$ be A-metric spaces.

A function $f: X \rightarrow Z$ is continuous at a point $x_{0} \in X$ iff it is sequentially continuous at $x_{0}$.

Lemma 2.22 Let $(X, A)$ be A-metric space, then the function $A(x, x, x, \ldots, x, y)$ is continuous in all of its arguments. In other words, if there exist sequences $\left\{x_{k}\right\}$ and $\left\{y_{k}\right\}$ such that $\lim _{k \rightarrow \infty} x_{k}=x$ and $\lim _{k \rightarrow \infty} y_{k}=y$ then $\lim _{k \rightarrow \infty} A\left(x_{k}, x_{k}, x_{k}, \ldots, x_{k}, y_{k}\right)=A(x, x, x, \ldots, x, y)$.

Proof Let $\left\{x_{k}\right\}$ and $\left\{y_{k}\right\}$ be convergent sequences in $(X, A)$. Let $\lim _{k \rightarrow \infty} x_{k}=x$ and $\lim _{k \rightarrow \infty} y_{k}=y$. Then given $\epsilon>0$, there exist $N_{1}, N_{2} \in \mathbb{N}$ such that, for all $k \geq N_{1}$, we get $A\left(x_{k}, x_{k}, x_{k}, \ldots, x_{k}, x\right)<\frac{\epsilon}{2(n-1)}$ and, for all $k \geq N_{2}$, we have $A\left(y_{k}, y_{k}, y_{k}, \ldots, y_{k}, y\right)<\frac{\epsilon}{2(n-1)}$. Put $N=\max \left\{N_{1}, N_{2}\right\}$, therefore, for every $k \geq N$, we have

$$
\begin{aligned}
A\left(x_{k}, x_{k}, x_{k}, \ldots, x_{k}, y_{k}\right) \leq & (n-1) A\left(x_{k}, x_{k}, x_{k}, \ldots, x_{k}, x\right)+A\left(x, x, x, \ldots, x, y_{k}\right) \\
= & (n-1) A\left(x_{k}, x_{k}, x_{k}, \ldots, x_{k}, x\right) \\
& +A\left(y_{k}, y_{k}, y_{k}, \ldots, y_{k}, x\right) \\
\leq & (n-1) A\left(x_{k}, x_{k}, x_{k}, \ldots, x_{k}, x\right) \\
& +(n-1) A\left(y_{k}, y_{k}, y_{k}, \ldots, y_{k}, y\right) \\
& +A(y, y, y, \ldots, y, x) \\
= & (n-1) \times \frac{\epsilon}{2(n-1)}+(n-1) \times \frac{\epsilon}{2(n-1)} \\
& +A(x, x, x, \ldots, x, y),
\end{aligned}
$$

which implies

$$
A\left(x_{k}, x_{k}, x_{k}, \ldots, x_{k}, y_{k}\right)-A(x, x, x, \ldots, x, y) \leq \epsilon
$$

On the other hand,

$$
\begin{aligned}
A(x, x, x, \ldots, x, y) \leq & (n-1) A\left(x, x, x, \ldots, x, x_{k}\right)+A\left(y, y, y, \ldots, y, x_{k}\right) \\
\leq & (n-1) A\left(x, x, x, \ldots, x, x_{k}\right) \\
& +(n-1) A\left(y, y, y, \ldots, y, y_{k}\right) \\
& +A\left(x_{k}, x_{k}, x_{k}, \ldots, x_{k}, y_{k}\right) \\
= & (n-1) \times \frac{\epsilon}{2(n-1)}+(n-1) \times \frac{\epsilon}{2(n-1)} \\
& +A\left(x_{k}, x_{k}, x_{k}, \ldots, x_{k}, y_{k}\right) \\
A(x, x, x, \ldots, x, y)- & A\left(x_{k}, x_{k}, x_{k}, \ldots, x_{k}, y_{k}\right) \leq \epsilon .
\end{aligned}
$$


Therefore by (2.3) and (2.4) we obtain $\left|A\left(x_{k}, x_{k}, x_{k}, \ldots, x_{k}, y_{k}\right)-A(x, x, x, \ldots, x, y)\right| \leq \epsilon$, i.e.

$$
\lim _{k \rightarrow \infty} A\left(x_{k}, x_{k}, x_{k}, \ldots, x_{k}, y_{k}\right)=A(x, x, x, \ldots, x, y)
$$

This completes the proof.

\section{Main result}

In this section, we obtain common coupled fixed point results of mappings satisfying more general contractive conditions in the framework of partially ordered $A$-metric spaces. We start with the following result.

Theorem 3.1 Let $(X, \leq, A)$ be a partially ordered complete A-metric space, $f, g: X^{2} \rightarrow X$ two maps such that;

(1) The pair $(f, g)$ has mixed weakly monotone property on $X$;

$x_{0} \leq f\left(x_{0}, y_{0}\right), f\left(y_{0}, x_{0}\right) \leq y_{0}$ or $x_{0} \leq g\left(x_{0}, y_{0}\right), g\left(y_{0}, x_{0}\right) \leq y_{0}$ for some $x_{0}, y_{0} \in X$.

(2) There exist $\alpha_{\imath} \geq 0, \imath=1, \ldots, 5$, satisfying $\sum_{l}^{5} \alpha_{\imath}<1$ and

$$
\begin{aligned}
& A(f(x, y), f(x, y), \ldots, f(x, y), g(u, v))+A(f(y, x), f(y, x), \ldots, f(y, x), g(v, u)) \\
& \leq \alpha_{1} D((x, y),(x, y),(x, y),(x, y), \ldots,(x, y),(u, v)) \\
&+\alpha_{2} D((x, y),(x, y), \ldots,(x, y),(f(x, y), f(y, x))) \\
&+\alpha_{3} D((u, v),(u, v), \ldots,(u, v),(g(u, v), g(v, u))) \\
&+\alpha_{4} D((x, y),(x, y), \ldots,(x, y),(g(u, v), g(v, u))) \\
&+\alpha_{5} D((u, v),(u, v), \ldots,(u, v),(f(x, y), f(y, x)))
\end{aligned}
$$

for all $x, y, u, v \in X$ with $x \leq u$ and $y \geq v$.

(3) Either $f$ or $g$ is continuous or $X$ has the following properties:

(a) If $\left\{x_{k}\right\}$ is an increasing sequence with $x_{k} \rightarrow x$, then $x_{k} \leq x$ for all $k \in \mathbb{N}$.

(b) If $\left\{y_{k}\right\}$ is a decreasing sequence with $y_{k} \rightarrow y$, then $y \leq y_{k}$ for all $k \in \mathbb{N}$.

Then $f$ and $g$ have a coupled common fixed point in $X$.

Proof Let $\left(x_{0}, y_{0}\right)$ be a given point in $X \times X$.

Choose $x_{1}=f\left(x_{0}, y_{0}\right), y_{1}=f\left(y_{0}, x_{0}\right), x_{2}=g\left(x_{1}, y_{1}\right)$, and $y_{2}=g\left(y_{1}, x_{1}\right)$.

From the condition $x_{0} \leq f\left(x_{0}, y_{0}\right), y_{0} \geq f\left(y_{0}, x_{0}\right)$, and the fact that $(f, g)$ has mixed weakly monotone property we have

$$
\begin{aligned}
& x_{1}=f\left(x_{0}, y_{0}\right) \leq g\left(f\left(x_{0}, y_{0}\right), f\left(y_{0}, x_{0}\right)\right)=g\left(x_{1}, y_{1}\right) \quad \Rightarrow \quad x_{1} \leq x_{2} \quad \text { and } \\
& x_{2}=g\left(x_{1}, y_{1}\right) \leq f\left(g\left(x_{1}, y_{1}\right), g\left(y_{1}, x_{1}\right)\right)=f\left(x_{2}, y_{2}\right) \quad \Rightarrow \quad x_{2} \leq x_{3} .
\end{aligned}
$$

Thus,

$$
\begin{aligned}
& y_{1}=f\left(y_{0}, x_{0}\right) \geq g\left(f\left(y_{0}, x_{0}\right), f\left(x_{0}, y_{0}\right)\right)=g\left(y_{1}, x_{1}\right) \quad \Rightarrow \quad y_{1} \geq y_{2} \quad \text { and } \\
& y_{2}=g\left(y_{1}, x_{1}\right) \geq f\left(g\left(y_{1}, x_{1}\right), g\left(x_{1}, y_{1}\right)\right)=f\left(y_{2}, x_{2}\right) \quad \Rightarrow \quad y_{2} \geq y_{3} .
\end{aligned}
$$


Continuing this way, we obtain

$$
\begin{aligned}
& x_{2 k+1}=f\left(x_{2 k}, y_{2 k}\right), \quad y_{2 k+1}=f\left(y_{2 k}, x_{2 k}\right) \quad \text { and } \\
& x_{2 k+2}=g\left(x_{2 k+1}, y_{2 k+1}\right), \quad y_{2 k+2}=g\left(y_{2 k+1}, x_{2 k+1}\right) \quad \text { for all } k \in \mathbb{N} .
\end{aligned}
$$

Therefore the sequences $\left\{x_{k}\right\}$ and $\left\{y_{k}\right\}$ are monotone:

$$
\begin{aligned}
& x_{0} \leq x_{1} \leq x_{2} \leq x_{3} \leq \cdots \leq x_{k} \leq x_{2 k+1} \leq x_{2 k+2} \leq \cdots \quad \text { and } \\
& y_{0} \geq y_{1} \geq y_{2} \geq y_{3} \geq \cdots \geq y_{k} \geq y_{2 k+1} \geq y_{2 k+2} \geq \cdots .
\end{aligned}
$$

Now we show that these sequences are Cauchy. From the contractive condition (3.1) we have for all $k \in \mathbb{N}$

$$
\begin{aligned}
& A\left(x_{2 k+1}, x_{2 k+1}, \ldots, x_{2 k+1}, x_{2 k+2}\right)+A\left(y_{2 k+1}, y_{2 k+1}, \ldots, y_{2 k+1}, y_{2 k+2}\right) \\
&= A\left(f\left(x_{2 k}, y_{2 k}\right), f\left(x_{2 k}, y_{2 k}\right), \ldots, f\left(x_{2 k}, y_{2 k}\right), g\left(x_{2 k+1}, y_{2 k+1}\right)\right) \\
&+A\left(f\left(y_{2 k}, x_{2 k}\right), f\left(y_{2 k}, x_{2 k}\right), \ldots, f\left(y_{2 k}, x_{2 k}\right), g\left(y_{2 k+1}, x_{2 k+1}\right)\right) \\
& \leq \alpha_{1} D\left(\left(x_{2 k}, y_{2 k}\right),\left(x_{2 k}, y_{2 k}\right), \ldots,\left(x_{2 k}, y_{2 k}\right),\left(x_{2 k+1}, y_{2 k+1}\right)\right) \\
&+\alpha_{2} D\left(\left(x_{2 k}, y_{2 k}\right),\left(x_{2 k}, y_{2 k}\right), \ldots,\left(x_{2 k}, y_{2 k}\right),\left(f\left(x_{2 k}, y_{2 k}\right), f\left(y_{2 k}, x_{2 k}\right)\right)\right) \\
&+\alpha_{3} D\left(\left(x_{2 k+1}, y_{2 k+1}\right),\left(x_{2 k+1}, y_{2 k+1}\right), \ldots,\left(x_{2 k+1}, y_{2 k+1}\right),\left(g\left(x_{2 k+1}, y_{2 k+1}\right), g\left(y_{2 k+1}, x_{2 k+1}\right)\right)\right) \\
&+\alpha_{4} D\left(\left(x_{2 k}, y_{2 k}\right),\left(x_{2 k}, y_{2 k}\right), \ldots,\left(x_{2 k}, y_{2 k}\right),\left(g\left(x_{2 k+1}, y_{2 k+1}\right), g\left(y_{2 k+1}, x_{2 k+1}\right)\right)\right) \\
&+\alpha_{5} D\left(\left(x_{2 k+1}, y_{2 k+1}\right),\left(x_{2 k+1}, y_{2 k+1}\right), \ldots,\left(x_{2 k+1}, y_{2 k+1}\right),\left(f\left(x_{2 k}, y_{2 k}\right), f\left(y_{2 k}, x_{2 k}\right)\right)\right) .
\end{aligned}
$$

Applying (3.2) we get

$$
\begin{aligned}
& A\left(x_{2 k+1}, x_{2 k+1}, \ldots, x_{(2 k+1)}, x_{2 k+2}\right)+A\left(y_{2 k+1}, y_{2 k+1}, \ldots, y_{(2 k+1)}, y_{2 k+2}\right) \\
& \leq \alpha_{1} D\left(\left(x_{2 k}, y_{2 k}\right),\left(x_{2 k}, y_{2 k}\right), \ldots,\left(x_{2 k}, y_{2 k}\right),\left(x_{2 k+1}, y_{2 k+1}\right)\right) \\
&+\alpha_{2} D\left(\left(x_{2 k}, y_{2 k}\right),\left(x_{2 k}, y_{2 k}\right), \ldots,\left(x_{2 k}, y_{2 k}\right),\left(x_{2 k+1}, y_{2 k+1}\right)\right) \\
&+\alpha_{3} D\left(\left(x_{2 k+1}, y_{2 k+1}\right),\left(x_{2 k+1}, y_{2 k+1}\right), \ldots,\left(x_{2 k+1}, y_{2 k+1}\right),\left(x_{2 k+2}, y_{2 k+2}\right)\right) \\
&+\alpha_{4} D\left(\left(x_{2 k}, y_{2 k}\right),\left(x_{2 k}, y_{2 k}\right), \ldots,\left(x_{2 k}, y_{2 k}\right),\left(x_{2 k+2}, y_{2 k+2}\right)\right) \\
&+\alpha_{5} D\left(\left(x_{2 k+1}, y_{2 k+1}\right),\left(x_{2 k+1}, y_{2 k+1}\right), \ldots,\left(x_{2 k+1}, y_{2 k+1}\right),\left(x_{2 k+1}, y_{2 k+1}\right)\right) \\
&= \alpha_{1} D\left(\left(x_{2 k}, y_{2 k}\right),\left(x_{2 k}, y_{2 k}\right), \ldots,\left(x_{2 k}, y_{2 k}\right),\left(x_{2 k+1}, y_{2 k+1}\right)\right) \\
&+\alpha_{2} D\left(\left(x_{2 k}, y_{2 k}\right),\left(x_{2 k}, y_{2 k}\right), \ldots,\left(x_{2 k}, y_{2 k}\right),\left(x_{2 k+1}, y_{2 k+1}\right)\right) \\
&+\alpha_{3} D\left(\left(x_{2 k+1}, y_{2 k+1}\right),\left(x_{2 k+1}, y_{2 k+1}\right), \ldots,\left(x_{2 k+1}, y_{2 k+1}\right),\left(x_{2 k+2}, y_{2 k+2}\right)\right) \\
&+\alpha_{4} D\left(\left(x_{2 k}, y_{2 k}\right),\left(x_{2 k}, y_{2 k}\right), \ldots,\left(x_{2 k}, y_{2 k}\right),\left(x_{2 k+2}, y_{2 k+2}\right)\right) \\
&= \alpha_{1} D\left(\left(x_{2 k}, y_{2 k}\right),\left(x_{2 k}, y_{2 k}\right), \ldots,\left(x_{2 k}, y_{2 k}\right),\left(x_{2 k+1}, y_{2 k+1}\right)\right) \\
&+\alpha_{2} D\left(\left(x_{2 k}, y_{2 k}\right),\left(x_{2 k}, y_{2 k}\right), \ldots,\left(x_{2 k}, y_{2 k}\right),\left(x_{2 k+1}, y_{2 k+1}\right)\right) \\
&+\alpha_{3} D\left(\left(x_{2 k+1}, y_{2 k+1}\right),\left(x_{2 k+1}, y_{2 k+1}\right), \ldots,\left(x_{2 k+1}, y_{2 k+1}\right),\left(x_{2 k+2}, y_{2 k+2}\right)\right)
\end{aligned}
$$




$$
\begin{aligned}
& +\alpha_{4} D\left(\left(x_{2 k}, y_{2 k}\right),\left(x_{2 k}, y_{2 k}\right), \ldots,\left(x_{2 k}, y_{2 k}\right),\left(x_{2 k+1}, y_{2 k+1}\right)\right) \\
& +\alpha_{4} D\left(\left(x_{2 k+1}, y_{2 k+1}\right),\left(x_{2 k+1}, y_{2 k+1}\right), \ldots,\left(x_{2 k+1}, y_{2 k+1}\right),\left(x_{2 k+2}, y_{2 k+2}\right)\right) \\
= & \left(\alpha_{1}+\alpha_{2}+\alpha_{4}\right) D\left(\left(x_{2 k}, y_{2 k}\right),\left(x_{2 k}, y_{2 k}\right), \ldots,\left(x_{2 k}, y_{2 k}\right),\left(x_{2 k+1}, y_{2 k+1}\right)\right) \\
& +\left(\alpha_{3}+\alpha_{4}\right) D\left(\left(x_{2 k+1}, y_{2 k+1}\right),\left(x_{2 k+1}, y_{2 k+1}\right), \ldots,\left(x_{2 k+1}, y_{2 k+1}\right),\left(x_{2 k+2}, y_{2 k+2}\right)\right) \\
= & \left(\alpha_{1}+\alpha_{2}+\alpha_{4}\right)\left[A\left(x_{2 k}, x_{2 k}, \ldots, x_{2 k}, x_{2 k+1}\right)+A\left(y_{2 k}, y_{2 k}, \ldots, y_{2 k}, y_{2 k+1}\right)\right] \\
& +\left(\alpha_{3}+\alpha_{4}\right)\left[A\left(x_{2 k+1}, x_{2 k+1}, \ldots, x_{2 k+1}, x_{2 k+2}\right)+A\left(y_{2 k+1}, y_{2 k+1}, \ldots, y_{2 k+1}, y_{2 k+2}\right)\right] .
\end{aligned}
$$

Similarly we obtain

$$
\begin{aligned}
& A\left(y_{2 k+1}, y_{2 k+1}, \ldots, y_{2 k+1}, y_{2 k+2}\right)+A\left(x_{2 k+1}, x_{2 k+1}, \ldots, x_{2 k+1}, x_{2 k+2}\right) \\
& \quad \leq\left(\alpha_{1}+\alpha_{2}+\alpha_{4}\right)\left[A\left(y_{2 k}, y_{2 k}, \ldots, y_{2 k}, y_{2 k+1}\right)+A\left(x_{2 k}, x_{2 k}, \ldots, x_{2 k}, x_{2 k+1}\right)\right] \\
& \quad+\left(\alpha_{3}+\alpha_{4}\right)\left[A\left(y_{2 k+1}, y_{2 k+1}, \ldots, y_{2 k+1}, y_{2 k+2}\right)+A\left(x_{2 k+1}, x_{2 k+1}, \ldots, x_{2 k+1}, x_{2 k+2}\right)\right] .
\end{aligned}
$$

From (3.4) and (3.5), we have

$$
\begin{aligned}
& 2\left[A\left(x_{2 k+1}, x_{2 k+1}, \ldots, x_{2 k+1}, x_{2 k+2}\right)+A\left(y_{2 k+1}, y_{2 k+1}, \ldots, y_{2 k+1}, y_{2 k+2}\right)\right] \\
& \quad \leq 2\left[\left(\alpha_{1}+\alpha_{2}+\alpha_{4}\right)\left[A\left(x_{2 k}, x_{2 k}, \ldots, x_{2 k}, x_{2 k+1}\right)+A\left(y_{2 k}, y_{2 k}, \ldots, y_{2 k}, y_{2 k+1}\right)\right]\right] \\
& \quad+2\left[\left(\alpha_{3}+\alpha_{4}\right)\left[A\left(x_{2 k+1}, x_{2 k+1}, \ldots, x_{2 k+1}, x_{2 k+2}\right)+A\left(y_{2 k+1}, y_{2 k+1}, \ldots, y_{2 k+1}, y_{2 k+2}\right)\right]\right] .
\end{aligned}
$$

This implies that

$$
\begin{aligned}
& {\left[A\left(x_{2 k+1}, x_{2 k+1}, \ldots, x_{2 k+1}, x_{2 k+2}\right)+A\left(y_{2 k+1}, y_{2 k+1}, \ldots, y_{2 k+1}, y_{2 k+2}\right)\right]\left[1-\left(\alpha_{3}+\alpha_{4}\right)\right]} \\
& \quad \leq\left(\alpha_{1}+\alpha_{2}+\alpha_{4}\right)\left[A\left(x_{2 k}, x_{2 k}, \ldots, x_{2 k}, x_{2 k+1}\right)+A\left(y_{2 k}, y_{2 k}, \ldots, y_{2 k}, y_{2 k+1}\right)\right] .
\end{aligned}
$$

Thus

$$
\begin{aligned}
& A\left(x_{2 k+1}, x_{2 k+1}, \ldots, x_{2 k+1}, x_{2 k+2}\right)+A\left(y_{2 k+1}, y_{2 k+1}, \ldots, y_{2 k+1}, y_{2 k+2}\right) \\
& \quad \leq \frac{\left(\alpha_{1}+\alpha_{2}+\alpha_{4}\right)}{\left(1-\left(\alpha_{3}+\alpha_{4}\right)\right)}\left[A\left(x_{2 k}, x_{2 k}, \ldots, x_{2 k}, x_{2 k+1}\right)+A\left(y_{2 k}, y_{2 k}, \ldots, y_{2 k}, y_{2 k+1}\right)\right] .
\end{aligned}
$$

Let $\delta=\left[\frac{\left(\alpha_{1}+\alpha_{2}+\alpha_{4}\right)}{\left(1-\left(\alpha_{3}+\alpha_{4}\right)\right)}\right]$, then $0 \leq \delta<1$ and

$$
\begin{gathered}
A\left(x_{2 k+1}, x_{2 k+1}, \ldots, x_{2 k+1}, x_{2 k+2}\right)+A\left(y_{2 k+1}, y_{2 k+1}, \ldots, y_{2 k+1}, y_{2 k+2}\right) \\
\quad \leq \delta\left(A\left(x_{2 k}, x_{2 k}, \ldots, x_{2 k}, x_{2 k+1}\right)+A\left(y_{2 k}, y_{2 k}, \ldots, y_{2 k}, y_{2 k+1}\right)\right)
\end{gathered}
$$

For all $k \in \mathbb{N}$, applying (3.1) again and by interchanging the roles of $f$ and $g$, we obtain

$$
\begin{aligned}
& A\left(x_{2 k+2}, x_{2 k+2}, \ldots, x_{2 k+2}, x_{2 k+3}\right)+A\left(y_{2 k+2}, y_{2 k+2}, \ldots, y_{2 k+2}, y_{2 k+3}\right) \\
& \quad \leq \delta\left(A\left(x_{2 k+1}, x_{2 k+1}, \ldots, x_{2 k+1}, x_{2 k+2}\right)+A\left(y_{2 k+1}, y_{2 k+1}, \ldots, y_{2 k+1}, y_{2 k+2}\right)\right)
\end{aligned}
$$


It follows from (3.6) that

$$
\begin{aligned}
A( & \left.x_{2 k+1}, x_{2 k+1}, \ldots, x_{2 k+1}, x_{2 k+2}\right)+A\left(y_{2 k+1}, y_{2 k+1}, \ldots, y_{2 k+1}, y_{2 k+2}\right) \\
& \leq \delta\left(A\left(x_{2 k}, x_{2 k}, \ldots, x_{2 k}, x_{2 k+1}\right)+A\left(y_{2 k}, y_{2 k}, \ldots, y_{2 k}, y_{2 k+1}\right)\right) \\
& \leq \delta\left(\delta\left(A\left(x_{2 k-1}, x_{2 k-1}, \ldots, x_{2 k-1}, x_{2 k}\right)+A\left(y_{2 k-1}, y_{2 k-1}, \ldots, y_{2 k-1}, y_{2 k}\right)\right)\right) \\
& =\delta\left(\delta\left(\delta\left(A\left(x_{2 k-2}, x_{2 k-2}, \ldots, x_{2 k-2}, x_{2 k-1}\right)+A\left(y_{2 k-2}, y_{2 k-2}, \ldots, y_{2 k-2}, y_{2 k-1}\right)\right)\right)\right) .
\end{aligned}
$$

This implies

$$
\begin{aligned}
& A\left(x_{2 k+1}, x_{2 k+1}, \ldots, x_{2 k+1}, x_{2 k+2}\right)+A\left(y_{2 k+1}, y_{2 k+1}, \ldots, y_{2 k+1}, y_{2 k+2}\right) \\
& \quad \leq \delta^{5}\left(A\left(x_{2 k-4}, x_{2 k-4}, \ldots, x_{2 k-4}, x_{2 k-3}\right)+A\left(y_{2 k-4}, y_{2 k-4}, \ldots, y_{2 k-4}, y_{2 k-3}\right)\right) \\
& \quad \vdots \\
& \quad \leq \delta^{2 k+1}\left(A\left(x_{0}, x_{0}, \ldots, x_{0}, x_{1}\right)+A\left(y_{0}, y_{0}, \ldots, y_{0}, y_{1}\right)\right) .
\end{aligned}
$$

Similarly, by (3.7) we get

$$
\begin{aligned}
& A\left(x_{2 k+2}, x_{2 k+2}, \ldots, x_{2 k+2}, x_{2 k+3}\right)+A\left(y_{2 k+2}, y_{2 k+2}, \ldots, y_{2 k+2}, y_{2 k+3}\right) \\
& \quad \leq \delta^{2 k+2}\left(A\left(x_{0}, x_{0}, \ldots, x_{0}, x_{1}\right)+A\left(y_{0}, y_{0}, \ldots, y_{0}, y_{1}\right)\right) .
\end{aligned}
$$

By Lemma 2.5 we have for all $k, m \in \mathbb{N}$ with $k \leq m$

$$
\begin{aligned}
A\left(x_{2 k+1}, x_{2 k+1}, \ldots, x_{2 k+1}, x_{2 m+1}\right) \leq & (n-1) A\left(x_{2 k+1}, x_{2 k+1}, \ldots, x_{2 k+1}, x_{2 k+2}\right) \\
& +A\left(x_{2 k+2}, x_{2 k+2}, \ldots, x_{2 k+2}, x_{2 m+1}\right)
\end{aligned}
$$

and

$$
\begin{aligned}
A\left(y_{2 k+1}, y_{2 k+1}, \ldots, y_{2 k+1}, y_{2 m+1}\right) \leq & (n-1) A\left(y_{2 k+1}, y_{2 k+1}, \ldots, y_{2 k+1}, y_{2 k+2}\right) \\
& +A\left(y_{2 k+2}, y_{2 k+2}, \ldots, y_{2 k+2}, y_{2 m+1}\right) .
\end{aligned}
$$

So we have

$$
\begin{aligned}
& A\left(x_{2 k+1}, x_{2 k+1}, \ldots, x_{2 k+1}, x_{2 m+1}\right)+A\left(y_{2 k+1}, y_{2 k+1}, \ldots, y_{2 k+1}, y_{2 m+1}\right) \\
& \leq(n-1) A\left(x_{2 k+1}, x_{2 k+1}, \ldots, x_{2 k+1}, x_{2 k+2}\right) \\
& \quad+(n-1) A\left(y_{2 k+1}, y_{2 k+1}, \ldots, y_{2 k+1}, y_{2 k+2}\right) \\
&+A\left(x_{2 k+2}, x_{2 k+2}, \ldots, x_{2 k+2}, x_{2 m+1}\right) \\
&+A\left(y_{2 k+2}, y_{2 k+2}, \ldots, y_{2 k+2}, y_{2 m+1}\right) \\
&=(n-1)\left[A\left(x_{2 k+1}, x_{2 k+1}, \ldots, x_{2 k+1}, x_{2 k+2}\right)+A\left(y_{2 k+1}, y_{2 k+1}, \ldots, y_{2 k+1}, y_{2 k+2}\right)\right] \\
& \quad+(n-1)\left[A\left(x_{2 k+2}, x_{2 k+2}, \ldots, x_{2 k+2}, x_{2 k+3}\right)+A\left(y_{2 k+2}, y_{2 k+2}, \ldots, y_{2 k+2}, y_{2 k+3}\right)\right] \\
& \vdots
\end{aligned}
$$




$$
\begin{aligned}
&+(n-1)\left[A\left(x_{2 m-1}, x_{2 m-1}, \ldots, x_{2 m-1}, x_{2 m}\right)+A\left(y_{2 m-1}, y_{2 m-1}, \ldots, y_{2 m-1}, y_{2 m}\right)\right] \\
&+\left[A\left(x_{2 m}, x_{2 m}, \ldots, x_{2 m}, x_{2 m+1}\right)+A\left(y_{2 m}, y_{2 m}, \ldots, y_{2 m}, y_{2 m+1}\right)\right] \\
& \Rightarrow \\
& A\left(x_{2 k+1}, x_{2 k+1}, \ldots, x_{2 k+1}, x_{2 m+1}\right)+A\left(y_{2 k+1}, y_{2 k+1}, \ldots, y_{2 k+1}, y_{2 m+1}\right) \\
& \leq(n-1)\left[A\left(x_{2 k+1}, x_{2 k+1}, \ldots, x_{2 k+1}, x_{2 k+2}\right)+A\left(y_{2 k+1}, y_{2 k+1}, \ldots, y_{2 k+1}, y_{2 k+2}\right)\right] \\
& \quad \vdots \\
& \quad+(n-1)\left[A\left(x_{2 m}, x_{2 m}, \ldots, x_{2 m}, x_{2 m+1}\right)+A\left(y_{2 m}, y_{2 m}, \ldots, y_{2 m}, y_{2 m+1}\right)\right] \\
&=(n-1)\left[\delta^{2 k+1}+\delta^{2 k+2}+\delta^{2 k+3}+\ldots+\delta^{2 m-1}+\delta^{2 m}\right] \\
& \quad \times\left[\left(A\left(x_{0}, x_{0}, \ldots, x_{0}, x_{1}\right)+A\left(y_{0}, y_{0}, \ldots, y_{0}, y_{1}\right)\right]\right. \\
& \Rightarrow \\
& A\left(x_{2 k+1}, x_{2 k+1}, \ldots, x_{2 k+1}, x_{2 m+1}\right)+A\left(y_{2 k+1}, y_{2 k+1}, \ldots, y_{2 k+1}, y_{2 m+1}\right) \\
& \leq(n-1)\left(\frac{\delta^{2 k+1}}{1-\delta}\right)\left(A\left(x_{0}, x_{0}, \ldots, x_{0}, x_{1}\right)+A\left(y_{0}, y_{0}, \ldots, y_{0}, y_{1}\right)\right) . \\
& \quad(n-1)
\end{aligned}
$$

Similarly, we have

$$
\begin{aligned}
& A\left(x_{2 k}, x_{2 k}, \ldots, x_{2 k}, x_{2 m+1}\right)+A\left(y_{2 k}, y_{2 k}, \ldots, y_{2 k}, y_{2 m+1}\right) \\
& \quad \leq(n-1)\left(\frac{\delta^{2 k}}{1-\delta}\right)\left(A\left(x_{0}, x_{0}, \ldots, x_{0}, x_{1}\right)+A\left(y_{0}, y_{0}, \ldots, y_{0}, y_{1}\right)\right)
\end{aligned}
$$

and

$$
\begin{aligned}
& A\left(x_{2 k}, x_{2 k}, \ldots, x_{2 k}, x_{2 m}\right)+A\left(y_{2 k}, y_{2 k}, \ldots, y_{2 k}, y_{2 m}\right) \\
& \leq(n-1)\left[\delta^{2 k}+\delta^{2 k+1}+\delta^{2 k+2}+\cdots+\delta^{2 m-1}\right] \\
& \quad \times {\left[\left(A\left(x_{0}, x_{0}, \ldots, x_{0}, x_{1}\right)+A\left(y_{0}, y_{0}, \ldots, y_{0}, y_{1}\right)\right]\right.} \\
&=(n-1)\left(\frac{\delta^{2 k}}{1-\delta}\right)\left(A\left(x_{0}, x_{0}, \ldots, x_{0}, x_{1}\right)+A\left(y_{0}, y_{0}, \ldots, y_{0}, y_{1}\right)\right) .
\end{aligned}
$$

Hence, for all $k, m \in \mathbb{N}$ with $k \leq m$, we have

$$
\begin{aligned}
& A\left(x_{k}, x_{k}, \ldots, x_{k}, x_{m}\right)+A\left(y_{k}, y_{k}, \ldots, y_{k}, y_{m}\right) \\
& \quad \leq(n-1)\left(\frac{\delta^{k}}{1-\delta}\right)\left(A\left(x_{0}, x_{0}, \ldots, x_{0}, x_{1}\right)+A\left(y_{0}, y_{0}, \ldots, y_{0}, y_{1}\right)\right) .
\end{aligned}
$$

Since $0 \leq \delta=\left[\frac{\left(\alpha_{1}+\alpha_{2}+\alpha_{4}\right)}{\left(1-\left(\alpha_{3}+\alpha_{4}\right)\right)}\right]<1$, we have

$$
\lim _{k, m \rightarrow \infty}\left(A\left(x_{k}, x_{k}, \ldots, x_{k}, x_{m}\right)+A\left(y_{k}, y_{k}, \ldots, y_{k}, y_{m}\right)\right)=0 \text {. }
$$

That is,

$$
\lim _{k, m \rightarrow \infty} A\left(x_{k}, x_{k}, \ldots, x_{k}, x_{m}\right)=\lim _{k, m \rightarrow \infty} A\left(y_{k}, y_{k}, \ldots, y_{k}, y_{m}\right)=0
$$


Therefore, $\left\{x_{k}\right\}$ and $\left\{y_{k}\right\}$ are both Cauchy sequences in $X$. By the completeness of $X$, there exist $x, y \in X$ such that $x_{k} \rightarrow x$ and $y_{k} \rightarrow y$ as $k \rightarrow \infty$.

We next show that the pair $(x, y)$ is a coupled common fixed point of $f$ and $g$.

Now, suppose $f$ is continuous, then we have

$$
\begin{aligned}
x & =\lim _{k \rightarrow \infty} x_{2 k+1}=\lim _{k \rightarrow \infty} f\left(x_{2 k}, y_{2 k}\right) \\
& =f\left(\lim _{k \rightarrow \infty} x_{2 k}, \lim _{k \rightarrow \infty} y_{2 k}\right) \\
& =f(x, y)
\end{aligned}
$$

and

$$
\begin{aligned}
y & =\lim _{k \rightarrow \infty} y_{2 k+1}=\lim _{k \rightarrow \infty} f\left(y_{2 k}, x_{2 k}\right) \\
& =f\left(\lim _{k \rightarrow \infty} y_{2 k}, \lim _{k \rightarrow \infty} x_{2 k}\right) \\
& =f(y, x) .
\end{aligned}
$$

Applying (3.1), we have

$$
\begin{aligned}
& A(f(x, y), f(x, y), \ldots, f(x, y), g(x, y))+A(f(y, x), f(y, x), \ldots, f(y, x), g(y, x)) \\
& \leq \alpha_{1} D((x, y),(x, y),(x, y),(x, y), \ldots,(x, y),(x, y)) \\
&+\alpha_{2} D((x, y),(x, y), \ldots,(x, y),(f(x, y), f(y, x))) \\
&+\alpha_{3} D((x, y),(x, y), \ldots,(x, y),(g(x, y), g(y, x))) \\
&+\alpha_{4} D((x, y),(x, y), \ldots,(x, y),(g(x, y), g(y, x))) \\
&+\alpha_{5} D((x, y),(x, y), \ldots,(x, y),(f(x, y), f(y, x))) \\
&= \alpha_{2} D((x, y),(x, y), \ldots,(x, y),(x, y)) \\
&+\alpha_{3} D((x, y),(x, y), \ldots,(x, y),(g(x, y), g(y, x))) \\
&+\alpha_{4} D((x, y),(x, y), \ldots,(x, y),(g(x, y), g(y, x))) \\
&+\alpha_{5} D((x, y),(x, y), \ldots,(x, y),(x, y)) \\
&=\left(\alpha_{3}+\alpha_{4}\right) D((x, y),(x, y), \ldots,(x, y),(g(x, y), g(y, x))) \\
&=\left(\alpha_{3}+\alpha_{4}\right)(A(x, x, \ldots, x, g(x, y))+A(y, y, \ldots, y, g(y, x))) .
\end{aligned}
$$

Therefore

$$
\begin{aligned}
& A(x, x, x, \ldots, x, g(x, y))+A(y, y, y, \ldots, y, g(y, x)) \\
& \quad \leq\left(\alpha_{3}+\alpha_{4}\right)(A(x, x, x, \ldots, x, g(x, y))+A(y, y, y, \ldots, y, g(y, x))) .
\end{aligned}
$$

Since $0 \leq\left(\alpha_{3}+\alpha_{4}\right)<1, A(x, x, x, \ldots, x, g(x, y))=A(y, y, y, \ldots, y, g(y, x))=0$.

That is, $g(x, y)=x$ and $g(y, x)=y$. This implies $(x, y)$ is a coupled fixed point of $g$. 
In a similar fashion, suppose $g$ is continuous, then we have

$$
\begin{aligned}
x & =\lim _{k \rightarrow \infty} x_{2 k+2}=\lim _{k \rightarrow \infty} g\left(x_{2 k+1}, y_{2 k+1}\right) \\
& =g\left(\lim _{k \rightarrow \infty} x_{2 k+1}, \lim _{k \rightarrow \infty} y_{2 k+1}\right) \\
& =g(x, y)
\end{aligned}
$$

and

$$
\begin{aligned}
y & =\lim _{k \rightarrow \infty} y_{2 k+2}=\lim _{k \rightarrow \infty} g\left(y_{2 k+1}, x_{2 k+1}\right) \\
& =g\left(\lim _{k \rightarrow \infty} y_{2 k+1}, \lim _{k \rightarrow \infty} x_{2 k+1}\right) \\
& =g(y, x) .
\end{aligned}
$$

Applying (3.1) again, we also get

$$
\begin{aligned}
& A(x, x, \ldots, x, f(x, y))+A(y, y, \ldots, y, f(y, x)) \\
& \quad \leq\left(\alpha_{2}+\alpha_{5}\right)(A(x, x, \ldots, x, f(x, y))+A(y, y, \ldots, y, f(y, x))) .
\end{aligned}
$$

This implies $f(x, y)=x$ and $f(y, x)=y$ and so $(x, y)$ is as well a coupled fixed point of $f$.

Therefore, $(x, y)$ is a coupled common fixed point of $f$ and $g$.

Finally, suppose $X$ satisfies hypotheses (3a) and (3b). Then by (3.3) we get $x_{k} \leq x$ and $y \leq y_{k}$ for all $k \in \mathbb{N}$. Applying Lemmas 2.5 and 2.6, we obtain

$$
\begin{aligned}
& D((x, y),(x, y), \ldots,(x, y),(f(x, y), f(y, x))) \\
& \leq(n-1) D\left((x, y),(x, y), \ldots,(x, y),\left(x_{2 k+2}, y_{2 k+2}\right)\right) \\
& +D\left(\left(x_{2 k+2}, y_{2 k+2}\right),\left(x_{2 k+2}, y_{2 k+2}\right), \ldots,\left(x_{2 k+2}, y_{2 k+2}\right),(f(x, y), f(y, x))\right) \\
& =(n-1) D\left((x, y),(x, y), \ldots,(x, y),\left(x_{2 k+2}, y_{2 k+2}\right)\right) \\
& +D\left(\left(g\left(x_{2 k+1}, y_{2 k+1}\right), g\left(y_{2 k+1}, x_{2 k+1}\right)\right),\left(g\left(x_{2 k+1}, y_{2 k+1}\right), g\left(y_{2 k+1}, x_{2 k+1}\right)\right), \ldots,\right. \\
& \left.\left(g\left(x_{2 k+1}, y_{2 k+1}\right), g\left(y_{2 k+1}, x_{2 k+1}\right)\right),(f(x, y), f(y, x))\right) \\
& \leq(n-1) D\left((x, y),(x, y), \ldots,(x, y),\left(x_{2 k+2}, y_{2 k+2}\right)\right) \\
& +A\left(g\left(x_{2 k+1}, y_{2 k+1}\right), g\left(x_{2 k+1}, y_{2 k+1}\right), \ldots,\left(g\left(x_{2 k+1}, y_{2 k+1}\right)\right), f(x, y)\right) \\
& +A\left(g\left(y_{2 k+1}, x_{2 k+1}\right), g\left(y_{2 k+1}, x_{2 k+1}\right), \ldots,\left(g\left(y_{2 k+1}, x_{2 k+1}\right)\right), f(y, x)\right) .
\end{aligned}
$$

This implies

$$
\begin{aligned}
D((x, y),(x, y), \ldots,(x, y),(f(x, y), f(y, x))) \\
\quad \leq(n-1) A\left(x, x, \ldots, x, x_{2 k+2}\right)+(n-1) A\left(y, y, \ldots, y, y_{2 k+2}\right) \\
\quad+A\left(g\left(x_{2 k+1}, y_{2 k+1}\right), g\left(x_{2 k+1}, y_{2 k+1}\right), \ldots,\left(g\left(x_{2 k+1}, y_{2 k+1}\right)\right), f(x, y)\right) \\
\quad+A\left(g\left(y_{2 k+1}, x_{2 k+1}\right), g\left(y_{2 k+1}, x_{2 k+1}\right), \ldots,\left(g\left(y_{2 k+1}, x_{2 k+1}\right)\right), f(y, x)\right) .
\end{aligned}
$$


By using (3.1) and interchanging the roles of $f$ with $g$ we obtain

$$
\begin{aligned}
& A\left(g\left(x_{2 k+1}, y_{2 k+1}\right), g\left(x_{2 k+1}, y_{2 k+1}\right), \ldots, g\left(x_{2 k+1}, y_{2 k+1}\right), f(x, y)\right) \\
& \quad+A\left(g\left(y_{2 k+1}, x_{2 k+1}\right), g\left(y_{2 k+1}, x_{2 k+1}\right), \ldots, g\left(y_{2 k+1}, x_{2 k+1}\right), f(y, x)\right) \\
& \leq \alpha_{1} D\left(\left(x_{2 k+1}, y_{2 k+1}\right),\left(x_{2 k+1}, y_{2 k+1}\right), \ldots,\left(x_{2 k+1}, y_{2 k+1}\right),(x, y)\right) \\
&+\alpha_{2} D\left(\left(x_{2 k+1}, y_{2 k+1}\right),\left(x_{2 k+1}, y_{2 k+1}\right), \ldots,\left(x_{2 k+1}, y_{2 k+1}\right),\left(g\left(x_{2 k+1}, y_{2 k+1}\right), g\left(y_{2 k+1}, x_{2 k+1}\right)\right)\right) \\
&+\alpha_{3} D((x, y),(x, y), \ldots,(x, y),(f(x, y), f(y, x))) \\
&+\alpha_{4} D\left(\left(x_{2 k+1}, y_{2 k+1}\right),\left(x_{2 k+1}, y_{2 k+1}\right), \ldots,\left(x_{2 k+1}, y_{2 k+1}\right),(f(x, y), f(y, x))\right) \\
&+\alpha_{5} D\left((x, y),(x, y), \ldots,(x, y),\left(g\left(x_{2 k+1}, y_{2 k+1}\right), g\left(y_{2 k+1}, x_{2 k+1}\right)\right)\right) \\
&= \alpha_{1} D\left(\left(x_{2 k+1}, y_{2 k+1}\right),\left(x_{2 k+1}, y_{2 k+1}\right), \ldots,\left(x_{2 k+1}, y_{2 k+1}\right),(x, y)\right) \\
&+\alpha_{2} D\left(\left(x_{2 k+1}, y_{2 k+1}\right),\left(x_{2 k+1}, y_{2 k+1}\right), \ldots,\left(x_{2 k+1}, y_{2 k+1}\right),\left(x_{2 k+2}, y_{2 k+2}\right)\right) \\
&+\alpha_{3} D((x, y),(x, y), \ldots,(x, y),(f(x, y), f(y, x))) \\
&+\alpha_{4} D\left(\left(x_{2 k+1}, y_{2 k+1}\right),\left(x_{2 k+1}, y_{2 k+1}\right), \ldots,\left(x_{2 k+1}, y_{2 k+1}\right),(f(x, y), f(y, x))\right) \\
&+\alpha_{5} D\left((x, y),(x, y), \ldots,(x, y),\left(x_{2 k+2}, y_{2 k+2}\right)\right) .
\end{aligned}
$$

It follows from (3.10) and (3.11) that

$$
\begin{aligned}
& D((x, y),(x, y), \ldots,(x, y),(f(x, y), f(y, x))) \\
& \quad \leq(n-1) A\left(x, x, \ldots, x, x_{2 k+2}\right)+(n-1) A\left(y, y, \ldots, y, y_{2 k+2}\right) \\
&+\alpha_{1} D\left(\left(x_{2 k+1}, y_{2 k+1}\right),\left(x_{2 k+1}, y_{2 k+1}\right), \ldots,\left(x_{2 k+1}, y_{2 k+1}\right),(x, y)\right) \\
&+\alpha_{2} D\left(\left(x_{2 k+1}, y_{2 k+1}\right),\left(x_{2 k+1}, y_{2 k+1}\right), \ldots,\left(x_{2 k+1}, y_{2 k+1}\right),\left(x_{2 k+2}, y_{2 k+2}\right)\right) \\
&+\alpha_{3} D((x, y),(x, y), \ldots,(x, y),(f(x, y), f(y, x))) \\
&+\alpha_{4} D\left(\left(x_{2 k+1}, y_{2 k+1}\right),\left(x_{2 k+1}, y_{2 k+1}\right), \ldots,\left(x_{2 k+1}, y_{2 k+1}\right),(f(x, y), f(y, x))\right) \\
&+\alpha_{5} D\left((x, y),(x, y), \ldots,(x, y),\left(x_{2 k+2}, y_{2 k+2}\right)\right) .
\end{aligned}
$$

Taking the limit as $k \rightarrow \infty$ in (3.12), we get

$$
\begin{aligned}
& D((x, y),(x, y), \ldots,(x, y),(f(x, y), f(y, x))) \\
& \leq(n-1) A(x, x, \ldots, x, x)+(n-1) A(y, y, \ldots, y, y) \\
&+\alpha_{1} D((x, y),(x, y), \ldots,(x, y),(x, y)) \\
&+\alpha_{2} D((x, y),(x, y), \ldots,(x, y),(x, y)) \\
&+\alpha_{3} D((x, y),(x, y), \ldots,(x, y),(f(x, y), f(y, x))) \\
&+\alpha_{4} D((x, y),(x, y), \ldots,(x, y),(f(x, y), f(y, x))) \\
&+\alpha_{5} D((x, y),(x, y), \ldots,(x, y),(x, y)) \\
&= \alpha_{3} D((x, y),(x, y), \ldots,(x, y),(f(x, y), f(y, x))) \\
&+\alpha_{4} D((x, y),(x, y), \ldots,(x, y),(f(x, y), f(y, x))) .
\end{aligned}
$$


Therefore,

$$
\begin{aligned}
& D((x, y),(x, y), \ldots,(x, y),(f(x, y), f(y, x))) \\
& \quad \leq\left(\alpha_{3}+\alpha_{4}\right) D((x, y),(x, y), \ldots,(x, y),(f(x, y), f(y, x))) .
\end{aligned}
$$

Since $\left(\alpha_{3}+\alpha_{4}\right)<1$ we have $D((x, y),(x, y), \ldots,(x, y),(f(x, y), f(y, x)))=0$. That is $f(x, y)=x$ and $f(y, x)=y$. This implies $(x, y)$ is a coupled fixed point of $f$.

Similarly, we can show that $g(x, y)=x$ and $g(y, x)=y$.

Hence, $f(x, y)=x=g(x, y)$ and $f(y, x)=y=g(y, x)$. Thus $(x, y)$ is a coupled common fixed point of $f$ and $g$. This completes the proof.

Theorem 3.2 In addition to the hypotheses of Theorem 3.1, if $X$ is a totally ordered set, then $f$ and $g$ have a unique coupled common fixed point. Furthermore, any fixed point off is a fixed point of $g$, and conversely.

Proof Let $X$ be a totally ordered set. Suppose $(x, y),\left(x^{*}, y^{*}\right)$ are coupled common fixed points of $f$ and $g$. That is, $f(x, y)=x, f(y, x)=y$, and $g\left(x^{*}, y^{*}\right)=x^{*}, g\left(y^{*}, x^{*}\right)=y^{*}$. We show that $x=x^{*}, y=y^{*}$, and subsequently $x=y$.

Observe that if $X$ is a totally ordered set, then, for every $(x, y),\left(x^{*}, y^{*}\right) \in X \times X$, there exists $(u, v) \in X \times X$ that is comparable to $(x, y)$ and $\left(x^{*}, y^{*}\right)$.

So we let $(x, y) \leq\left(x^{*}, y^{*}\right)$ without loss of generality, then it follows from Lemma 2.6 and Theorem 3.1 that

$$
\begin{aligned}
& D\left((x, y),(x, y), \ldots,(x, y),\left(x^{*}, y^{*}\right)\right) \\
&= A\left(x, x, \ldots, x, x^{*}\right)+A\left(y, y, \ldots, y, y^{*}\right) \\
&= A\left(f(x, y), f(x, y), \ldots, f(x, y), g\left(x^{*}, y^{*}\right)\right) \\
&+A\left(f(y, x), f(y, x), \ldots, f(y, x), g\left(y^{*}, x^{*}\right)\right) \\
& \leq \alpha_{1} D\left((x, y),(x, y), \ldots,(x, y),\left(x^{*}, y^{*}\right)\right) \\
&+\alpha_{2} D((x, y),(x, y), \ldots,(x, y),(f(x, y), f(y, x))) \\
&+\alpha_{3} D\left(\left(x^{*}, y^{*}\right),\left(x^{*}, y^{*}\right), \ldots,\left(x^{*}, y^{*}\right),\left(g\left(x^{*}, y^{*}\right), g\left(y^{*}, x^{*}\right)\right)\right) \\
&+\alpha_{4} D\left((x, y),(x, y), \ldots,(x, y),\left(g\left(x^{*}, y^{*}\right), g\left(y^{*}, x^{*}\right)\right)\right) \\
&+\alpha_{5} D\left(\left(x^{*}, y^{*}\right),\left(x^{*}, y^{*}\right), \ldots,\left(x^{*}, y^{*}\right),(f(x, y), f(y, x))\right) \\
&= \alpha_{1} D\left((x, y),(x, y), \ldots,(x, y),\left(x^{*}, y^{*}\right)\right) \\
&+\alpha_{2} D((x, y),(x, y), \ldots,(x, y),(x, y)) \\
&+\alpha_{3} D\left(\left(x^{*}, y^{*}\right),\left(x^{*}, y^{*}\right), \ldots,\left(x^{*}, y^{*}\right),\left(x^{*}, y^{*}\right)\right) \\
&+\alpha_{4} D\left((x, y),(x, y), \ldots,(x, y),\left(x^{*}, y^{*}\right)\right) \\
&+\alpha_{5} D\left(\left(x^{*}, y^{*}\right),\left(x^{*}, y^{*}\right), \ldots,\left(x^{*}, y^{*}\right),(x, y)\right) \\
&= \alpha_{1} D\left((x, y),(x, y), \ldots,(x, y),\left(x^{*}, y^{*}\right)\right) \\
&+\alpha_{4} D\left((x, y),(x, y), \ldots,(x, y),\left(x^{*}, y^{*}\right)\right)
\end{aligned}
$$




$$
\begin{gathered}
+\alpha_{5} D\left(\left(x^{*}, y^{*}\right),\left(x^{*}, y^{*}\right), \ldots,\left(x^{*}, y^{*}\right),(x, y)\right) \\
=\left(\alpha_{1}+\alpha_{4}+\alpha_{5}\right) D\left((x, y),(x, y), \ldots,(x, y),\left(x^{*}, y^{*}\right)\right) .
\end{gathered}
$$

Since $0 \leq\left(\alpha_{1}+\alpha_{4}+\alpha_{5}\right)<1$, we have $D\left((x, y),(x, y), \ldots,(x, y),\left(x^{*}, y^{*}\right)\right)=0$, which implies $x=x^{*}$ and $y=y^{*}$.

Proceeding, we show that any fixed point of $f$ is a fixed point of $g$, and conversely. Applying Lemma 2.6 and Theorem 3.1 we have

$$
\begin{aligned}
& A(x, x, \ldots, x, y)+A(y, y, \ldots, y, x) \\
&= A(f(x, y), f(x, y), \ldots, f(x, y), g(y, x)) \\
&+A(f(y, x), f(y, x), \ldots, f(y, x), g(x, y)) \\
& \leq \alpha_{1} D((x, y),(x, y), \ldots,(x, y),(y, x)) \\
&+\alpha_{2} D((x, y),(x, y), \ldots,(x, y),(f(x, y), f(y, x))) \\
&+\alpha_{3} D((y, x),(y, x), \ldots,(y, x),(g(y, x), g(x, y))) \\
&+\alpha_{4} D((x, y),(x, y), \ldots,(x, y),(g(y, x), g(x, y))) \\
&+\alpha_{5} D((y, x),(y, x), \ldots,(y, x),(f(x, y), f(y, x))) \\
&= \alpha_{1} D((x, y),(x, y), \ldots,(x, y),(y, x)) \\
&+\alpha_{2} D((x, y),(x, y), \ldots,(x, y),(x, y)) \\
&+\alpha_{3} D((y, x),(y, x), \ldots,(y, x),(y, x)) \\
&+\alpha_{4} D((x, y),(x, y), \ldots,(x, y),(y, x)) \\
&+\alpha_{5} D((y, x),(y, x), \ldots,(y, x),(x, y)) \\
&= \alpha_{1} D((x, y),(x, y), \ldots,(x, y),(y, x)) \\
&+\alpha_{4} D((x, y),(x, y), \ldots,(x, y),(y, x)) \\
&+\alpha_{5} D((x, y),(x, y), \ldots,(x, y),(y, x)) .
\end{aligned}
$$

Therefore

$$
A(x, x, \ldots, x, y)+A(y, y, \ldots, y, x) \leq\left(\alpha_{1}+\alpha_{4}+\alpha_{5}\right)(A(x, x, \ldots, x, y)+A(y, y, \ldots, y, x)) .
$$

Since $0 \leq\left(\alpha_{1}+\alpha_{4}+\alpha_{5}\right)<1, A(x, x, \ldots, x, y)+A(y, y, \ldots, y, x)=0$.

That is, $x=y$. The coupled common fixed point of $f$ and $g$ is unique.

If $n=3, \alpha_{1}=p, \alpha_{2}=q, \alpha_{3}=r, \alpha_{4}=\alpha_{5}=s$ in Theorem 3.1 with $D_{A}=D_{S}$, then we obtain the main result in [26].

If $n=2, \alpha_{1}=p, \alpha_{2}=q, \alpha_{3}=r, \alpha_{4}=\alpha_{5}=s$, in Theorem 3.1 with $D_{A}=D_{d}$, then we get the main result in [7].

Example 3.3 Let $(\mathbb{R}, \leq, A)$ be a totally ordered complete $A$-metric space with $A$-metric defined as in Example 2.3. Let $f, g: \mathbb{R}^{2} \rightarrow \mathbb{R}$ be two maps defined by $f(x, y)=\frac{6 x-3 y+24 n-3}{24 n}$ and $g(x, y)=\frac{8 x-4 y+32 n-4}{32 n}$ for all $n \geq 1$. 
The pair $(f, g)$ has the mixed weakly monotone property on $\mathbb{R}$ and

$$
\begin{aligned}
A( & (x, y), f(x, y), \ldots, f(x, y), g(u, v))+A(f(y, x), f(y, x), \ldots, f(y, x), g(v, u)) \\
= & (n-1)|f(x, y)-g(u, v)|+(n-1)|f(y, x)-g(v, u)| \\
= & (n-1)\left|\frac{6 x-3 y+24 n-3}{24 n}-\frac{8 u-4 v+32 n-4}{32 n}\right| \\
& \quad+(n-1)\left|\frac{6 y-3 x+24 n-3}{24 n}-\frac{8 v-4 u+32 n-4}{32 n}\right| \\
= & \frac{(n-1)}{768 n}|192(x-u)+96(y-v)|+\frac{(n-1)}{768 n}|192(y-v)+96(x-u)| \\
\leq & \frac{192(n-1)}{768 n}(|x-u|+|y-v|+|y-v|+|x-u|) \\
= & \frac{(n-1)}{2 n}(|x-u|+|y-v|) .
\end{aligned}
$$

Then the contractive condition (3.2) is satisfied with $\alpha_{1}=\frac{(n-1)}{n}, \alpha_{2}=\alpha_{3}=\alpha_{4}=\alpha_{5}=0$. Moreover, $(1,1)$ is the unique coupled common fixed point of $f$ and $g$.

\section{Competing interests}

The authors declare that they have no competing interests.

\section{Authors' contributions}

All authors contributed equally and significantly in writing this paper. All authors read and approved the final manuscript.

\section{Author details}

${ }^{1}$ Department of Mathematics and Applied Mathematics, University of Pretoria, Hatfield, Pretoria, South Africa.

${ }^{2}$ Department of Mathematics, Bayero University Kano, P.M.B. 3011, Kano, Nigeria. ${ }^{3}$ Department of Mathematics, Kano University of Science and Technology, P.M.B. 3042, Wudil, Kano, Nigeria.

\section{Acknowledgements}

The authors are grateful to the reviewers for their helpful comments.

\section{Received: 31 December 2014 Accepted: 14 April 2015 Published online: 06 May 2015}

\section{References}

1. Dhage, BC: Generalized metric spaces mappings with fixed point. Bull. Calcutta Math. Soc. 84, 329-336 (1992)

2. Gähler, S: 2-metriche raume und ihre topologische strukture. Math. Nachr. 26, 115-148 (1963)

3. Sedghi, S, Shobe, N, Zhou, H: A common fixed point theorem in D*-metric spaces. Fixed Point Theory Appl. 2007, Article ID 027906 (2007)

4. Sedghi, S, Shobe, N, Aliouche, A: A generalization of fixed point theorems in S-metric spaces. Mat. Vesn. 64(3), 258-266 (2012)

5. Mustafa, Z, Sims, B: A new approach to generalized metric spaces. J. Nonlinear Convex Anal. 7(2), $289-297$ (2006)

6. Gähler, S: Zur geometric 2-metriche raume. Rev. Roum. Math. Pures Appl. 11, 664-669 (1966)

7. Ha, KIS, Cho, YJ, White, A: Strictly convex and 2-convex 2-normed spaces. Math. Jpn. 33(3), 375-384 (1988)

8. Sharma, AK: A note on fixed points in 2-metric spaces. Indian J. Pure Appl. Math. 11(2), 1580-1583 (1980)

9. Dhage, BC: A study of some fixed point theorem. Ph.D. thesis, Marathwada University, Aurangabad, India (1984)

10. Dhage, BC: On generalized metric spaces and topological structure. II. Pure Appl. Math. Sci. 40, 37-41 (1994)

11. Dhage, BC: Generalized metric spaces and topological structure. I. An. Ştiinţ. Univ. 'Al.I. Cuza' laşi, Mat. 46, 3-24 (2000)

12. Naidu, SVR, Rao, KPR, Srinivasa, N: On the topology of D-metric spaces and the generation of $D$-metric spaces from metric spaces. Int. J. Math. Math. Sci. 51, 2719-2740 (2004)

13. Naidu, SVR, Rao, KPR, Srinivasa, N: On the concepts of balls in a D-metric space. Int. J. Math. Math. Sci. 1, 133-141 (2005)

14. Mustafa, Z, Sims, B: Some results concerning D-metric spaces. In: Proceedings of the International Conferences on Fixed Point Theory and Applications, Valencia, Spain, pp. 189-198 (2003)

15. Mustafa, Z, Obiedat, H, Awawdeh, F: Some common fixed point theorems for mapping on complete G-metric spaces. Fixed Point Theory Appl. 2008, Article ID 189870 (2008)

16. Sedghi, S, Rao, KPR, Shobe, N: Common fixed point theorems for six weakly compatible mappings in $D^{*}$-metric spaces. Int. J. Math. Math. Sci. 6, 225-237 (2007)

17. Samet, B: Coupled fixed point theorems for a generalized Meir-Keeler contraction in partially ordered metric spaces. Nonlinear Anal. 72, 4508-4517 (2010) 
18. Sedghi, S, Dung, NV: Fixed point theorems on S-metric spaces. Mat. Vesn. 66(1), 113-124 (2014)

19. Lakshmikantham, V, Ćirić, Ll: Coupled fixed point theorems for nonlinear contractions in partially ordered metric spaces. Nonlinear Anal. 70(12), 4341-4349 (2009)

20. Berinde, V, Vetro, F: Common fixed points of mappings satisfying implicit contractive conditions. Fixed Point Theory Appl. 2012, Article ID 105 (2012)

21. Bhaskar, TG, Lakshmikantham, V: Fixed point theorems in partially ordered metric spaces and applications. Nonlinear Anal. 65(7), 1379-1393 (2006)

22. Choudhurya, BS, Kundu, A: A coupled coincidence point result in partially ordered metric spaces for compatible mappings. Nonlinear Anal. 73, 2524-2531 (2010)

23. Agarwal, RP, El-Gebeily, MA, O’Regan, D: Generalized contractions in partially ordered metric spaces. Appl. Anal. 87, $1-8(2008)$

24. Berinde, $\mathrm{V}$ : Generalized coupled fixed point theorems for mixed monotone mappings in partially ordered metric spaces. Nonlinear Anal. 74(18), 7347-7355 (2011)

25. Kadelburg, Z, Pavlović, M, Radenović, S: Common fixed point theorems for ordered contractions and quasicontractions in ordered cone metric spaces. Comput. Math. Appl. 59, 3148-3159 (2010)

26. Gordji, ME, Ramezani, M, Cho, YJ, Akbartabar, E: Coupled common fixed point theorems for mixed weakly monotone mappings in partially ordered metric spaces. Fixed Point Theory Appl. 2012, Article ID 95 (2012)

27. Dung, NV: On coupled common fixed points theorem for mixed weakly monotone maps in partially ordered S-metric spaces. Fixed Point Theory Appl. 2013, Article ID 48 (2013)

\section{Submit your manuscript to a SpringerOpen ${ }^{\ominus}$ journal and benefit from:}

- Convenient online submission

Rigorous peer review

- Immediate publication on acceptance

- Open access: articles freely available online

- High visibility within the field

- Retaining the copyright to your article 